\title{
growth and change
}

\section{Short-Run Dynamics of Income Disparities and Regional Cycle Synchronization in the U.S.}

\author{
HASAN ENGIN DURAN
}

\begin{abstract}
Since the 1990s, the issue of regional income convergence and its long-term tendencies has been thoroughly and heatedly discussed. Much less attention, however, has been devoted to the short-run dynamics of regional convergence. In particular, three important aspects have not yet been adequately addressed. First, it is indeed essential to understand whether regional disparities manifest a tendency to move systematically along the national cycle. Then, if this happens to be the case, it becomes crucial to know whether 1) these movements are pro- or counter-cyclical,2) the cyclical evolution of the disparities is a consequence of differences in the timing with which the business cycle is felt in regions or it is motivated by the amplitude differences across local cyclical swings. In this paper, we shed light on these issues using data on personal income for the 48 coterminous U.S. states between 1969 and 2008 . Our results indicate that income disparities do not move randomly in the short run but follow a distinct cyclical pattern, moving either pro- or counter-cyclically depending on the period of analysis. These patterns are probably explained by the changes in the direction of capital and labor flows that favor developed or poorer states in different periods. As for the underlying mechanism, it appears that the short-run evolution of the disparities in recent years is largely a consequence of differences in the timing with which the business cycle is felt across states rather than the outcome of amplitude differences across local cyclical swings.
\end{abstract}

$\mathrm{I}$ $\mathrm{n}$ the literature on economic convergence, much attention has been devoted to the analysis of the evolution of regional disparities. In almost all cases, these studies have implicitly adopted a long-run perspective (Barro and Sala-i-Martin 1991; Rey and Montouri 1999). This is probably motivated by the fact that the most commonly adopted empirical tools are derived, more or less directly, from the traditional neoclassical model that, as is well known, describes a monotone path along which, under certain assumptions on production, technology, and preferences, each economic system converges toward a stable long-run dynamic equilibrium. The short-term dynamics and,

Hasan Engin Duran is an Assistant Professor of Economics at the City and Regional Planning Department, Izmir Institute of Technology, Izmir, Turkey. He obtained his PhD degree in Economics from Ca' Foscari University of Venice, Italy. His email address is: enginduran@iyte.edu.tr. The author is heartily grateful to Prof. Stefano Magrini and Prof. Margherita Gerolimetto for their priceless help and supervision. Funding of research for this study has been provided by Ca' Foscari Univesity of Venice under the research project titled "Short-run dynamics of income disparities".

Submitted November 2011; revised April 2012; accepted June 2012.

(C) 2014 Wiley Periodicals, Inc 
in particular, the interconnections between the disparities across economic systems (e.g., between regions) and the aggregate economic cycle have received very limited attention.

In spite of this, the few studies that have been confronted with this topic seem to suggest that regional disparities can vary significantly along the aggregate economic cycle. This result, if confirmed, has extremely important implications both for the empirical analysis of convergence and for regional economic policy.

On the one hand, because time series on income are usually quite short at the regional level, if regional disparities are shown to move significantly along the business cycle, then the period of analysis should be chosen with great care so to avoid it could affect the results (Magrini 1999; Pekkala 2000). Indeed, if regional disparities move, say, in an anti-cyclical fashion, i.e., increasing during the economic downturn and decreasing during the expansion phase, the choice of a period of analysis that does not contain entirely both phases of the cycle is likely to produce misleading results due to an overestimation of the tendency toward convergence (divergence) when the period of analysis excludes a part of the contraction (expansion) phase.

With regard to the implications for regional economic policy, it is important to emphasize that the recognition and quantification of a short-term component in the dynamics of regional disparities, as well as the causes of this component, would help understanding the extend to which policy interventions are needed in order to absorb structural and long-run regional differences. In a European perspective, in particular, assuming that regional disparities move in an anti-cyclical fashion, if the widening of the disparities during a recession is such to undermine the overall objective of social and territorial cohesion within the Union, it may be appropriate to put in place additional resources explicitly targeted to the containment of these dynamics. Conversely, if regional disparities demonstrate a pro-cyclical component, the reduction of disparities that take place during an economic downturn can be considered rather positively as it eases the pressure on resources to be devoted to the objective of territorial cohesion during the contraction phases.

Most of the studies dealing with the short-term evolution of regional disparities report evidence in favor of a pro-cyclical behavior. This finding implies that regional disparities move in the same direction as the national economic cycle and, therefore, tend to increase during expansion periods and diminish in times of recession. Some examples are Azzoni (2001) who studies the link between economic growth and regional disparities across Brazilian States between 1939 and 1995, Dewhurst (1998) who analyzes income disparities among 63 UK counties between 1984 and 1993, Chatterji and Dewhurst (1996) who focus on the disparities across counties and regions in the UK between 1977 and 1991, Petrakos and Saratsis (2000), who study inequalities among Greek prefectures between 1970 and 1995, Terassi (1999) who analyzes the divergence and convergence patterns among 20 Italian regions between 1953 and 1993, and Petrakos, Rodriquez-Pose, and Rovolis (2005) who focus on the disparities across EU countries between 1960 and 2000. 
From a theoretical point of view, the debate on how existing studies interpret the pro-cyclicality of disparities is far from clear cut. On the one hand, Petrakos, Rodriquez-Pose, and Rovolis (2005) and Petrakos and Saratsis (2000) try to interpret the pro-cyclical disparities by referring to Berry's (1988) explanations which are in line with the spatially cumulative nature of growth (Hirschman 1958; Myrdal 1957), growth pole theory (Perroux 1970) and agglomeration economies (Krugman 1991). According to this view, expansion phases begin in more developed and metropolitan areas where agglomeration and market size create a lead over other regions. As a consequence, regional inequalities intensify during times of expansion since economic growth that starts from poles of concentration (i.e., metropolitan centers) does not spread to the rest of the country automatically (Petrakos, Rodriquez-Pose, and Rovolis 2005). By contrast, developed areas suffer more than other regions during recessions and therefore income inequalities decrease (Petrakos and Saratsis 2000).

On the other hand, an alternative explanation of pro-cyclicality is provided by Rodriquez-Pose and Fratesi (2007). They show that most Southern European countries exhibit pro-cyclical regional disparities between 1980 and 2005. These countries leave sheltered regions in their rural areas. Sheltered regions are isolated economies that are mostly dependent on the agriculture sector, government transfers, and public employment. Therefore, these regions are not fit enough to compete with the rest of the economy and can not use their potential for convergence, which is generally available during the expansion periods. By contrast, in recessions they do not suffer as much as other regions and, therefore, tend to converge to richer regions. This view is consistent with the explanations of Azzoni (2001) who states that regional inequalities and speed of convergence oscillates over time in a pro-cyclical fashion where during the periods of fast demand growth developed regions are better prepared to face growing demand than poorer regions since richer regions have more dynamic sectors (i.e., manufacturing) in their production structure. By contrast, it is likely that these regions are worse affected from an economic downturn.

Apart from the pro-cyclical findings, there are some other studies that find evidence of anti-cyclical regional disparities. Pekkala (2000) investigates inequalities across 88 Finnish small-scale subregions between 1988 and 1995 by using distribution dynamics approach. She finds evidence of anti-cyclical regional disparities and mentions that income mobility of subregions within the cross-sectional distribution is high (low) during boom (recession) times and thus regional disparities tend to decrease (increase). She explains counter-cyclicality of disparities by referring to the patterns of migration within Finland and the effectiveness of regional policies. For the former argument, she states that the rate of worker migration in Finland is high during the boom times and low during economic downturns. Since labor moves toward developed subregions during expansions, spatial differences in per capita incomes tend to diminish (Pekkala 2000). Conversely, inequalities increase during recessions since the worker migration stagnates. In total, this pattern is consistent with the view that supports the equilibrating role of labor mobility in the short run. The latter argument refers to the effectiveness of 
regional policy and its cohesive effect during the upswing years of the economic cycle in which resources devoted to pursuing regional equality are more available than the downswing years (Pekkala 2000).

Finally, with regard to the studies on the U.S., while many authors have focused on the long-term patterns of regional inequalities (Fan and Casetti 1994; Kim 1998; Mitchener and McLean 1999) much less attention has been paid to the short-term dynamics. For the long-term patterns, Kim (1998) finds evidence of income divergence during the nineteenth century and convergence during the first half of the twentieth century. Consistent with Kim, Fan and Casetti (1994) recognize three remarkable periods of regional inequalities. The first one is referred to as the "spatial polarization" era started in the early 1800s in which the widening of the manufacturing belt in Northeast and Midwest states and the agglomeration of manufacturing attracted capital and labor inflows that favored these core regions and, therefore, intensified the income polarization and thus inequalities increased. The second period is referred to as the "Polarization Reversal" era during the first half of the twentieth century in which inequalities and polarization significantly decreased since agglomeration advantages and the direction of factor flows reversed and favored the peripheral locations due to lower labor and land costs, less unionization, finer climate and amenities. Finally, the third period that runs from the mid 1970s is an era of polarization and spatial structuring in which high-tech industries and services became new leading industries that are spatially selective and favor the metropolitan areas due to their advantages in infrastructure, communication systems, and quality of human resources. Therefore, during this period, relocation of capital and labor that moves toward selective locations (i.e., high-tech states) induces the polarization and income inequalities across states.

Regarding the short-term evolution of regional disparities in the U.S., the few existing studies indicate mixed results. While Dimelis and Livada (1999) who focus on income distributions in the U.S. between 1947 and 1989, Mendershausen (1946) and Kuznets (1953), who analyze the patterns of income inequality during the interwar periods, find evidence of counter-cyclical disparities, Quah (1996) finds no evidence of the impact of business cycles on the income disparities across 48 U.S. states between 1948 and 1990.

The present article tries to extend the literature in several directions. First, the relationship between regional disparities and business cycle might not be constant over time. Despite this, with the only exception of Rodriquez-Pose and Fratesi (2007), none of the existing studies have attempted to analyze the change in this relationship over time. Here, we try to fill the gap and investigate the evolution of this relationship. ${ }^{1} \mathrm{We}$ argue that income disparities may not always follow a pro- or anti-cyclical pattern but the type of cyclicality switches over time which is a fact, possibly, explained by the changes in the direction of capital and labor flows that favor developed or poorer states in different periods (Fan and Casetti 1994). This argumentation constitutes our first contribution to the existing literature in this field. Furthermore, it is important to emphasize that, to our knowledge, there appears to be no explicit theoretical framework 
that explains the short-term cyclical evolution of regional inequalities in the literature. That is why our work, which presents results on empirical grounds, might be seen as a stimulus for theoretical research.

Second, as far as we know, none of the studies on the short-run behavior of regional disparities have attempted to investigate the dynamics behind it. However, recognizing these dynamics might help us understanding the short-run behavior of disparities. In particular, we consider two short-run mechanisms behind the evolution of the disparities: disparities might evolve as a consequence of differences in the timing with which the business cycle is felt across regional economies; alternatively, the evolution of disparities might be motivated by amplitude differences across local cyclical swings.

Third, to our knowledge all existing studies define the national business cycle by referring directly to the growth rate of the aggregate economy. Therefore, positive growth years are interpreted as expansion periods and negative growth years are interpreted as recessions. However, we prefer to define the business cycle in a wider sense and, therefore, use deviation cycles, i.e., the fluctuations of the aggregate economy around its deterministic trend, so that for an economy to experience a recession it is sufficient that its actual growth rate is smaller than its trend growth. As argued also by other scholars (Hodrick and Prescott 1997; Zarnowitz and Ozyildirim 2006) deviation cycles are known to be more relevant than classical cycles during the postwar period in the U.S since the volatility of output considerably decreased. Deviation cycles, therefore, include more fluctuations with adequate durations and amplitudes.

In this paper, we intend to characterize the short-run behavior of income disparities across U.S. states in relation to the national business cycle. Our set of research questions are as follows:

1. Is there a relationship between the U.S. business cycle and income disparities across states? If so, do income disparities move pro-cyclically or anti-cyclically? Does this relationship change over time?

2. Are there meaningful state-specific cycles? Are there important differences in the timing and amplitudes of the cycles of the states? How do the differences in timing and amplitudes change over time?

3. What are the short-run driving forces behind the evolution of income disparities? Do the differences in amplitudes or timing across state cycles drive the evolution of income disparities? Which mechanism is more important?

The organization of the paper is as follows. In the second section, we implement a regression analysis in order to characterize the short-run behavior of income disparities. In the third section, we show how sizable are differences in amplitudes and timing across state cycles by using information obtained from the turning points of state cycles. In the fourth section, using Cholesky variance decompositions, we analyze 
whether amplitude or timing differences across states tend to be the major short-run driver of income disparities. Finally, the fifth section concludes the paper.

\section{Characterizing the Short-Run Behavior of Regional Disparities}

One of the main objectives of this study is to characterize the short-run behavior of income disparities across states. Therefore, in this part, we try to understand whether income disparities change in response to aggregate fluctuations of the economy. To do so, we use data on per capita real personal income net of current transfer receipts (quarterly) series for U.S. states over the period between 1969:1 and 2008:4 provided by the Bureau of Economic Analysis. Regarding the choice of spatial units, although there are 51 states in the U.S., we prefer to exclude Alaska, Hawaii, and the District of Columbia as commonly done in the literature and focus on the remaining 48 coterminous states.

Measuring the income inequalities across states is a first and essential step in our study. A variety of indices has been employed in order to measure regional inequalities in the literature (Cowell 2008; Firebaugh 2003). Here, we prefer using three of the most commonly adopted types. The first one is cross-sectional coefficient of variation of per capita incomes across states:

$$
C V_{t}=\frac{\sqrt{\sum_{i=1}^{n}\left(R P I_{i, t}-R \bar{P} I_{t}\right)^{2} /(n-1)}}{R \bar{P} I_{t}}
$$

where $R P I_{i, t}$ is the level of per capita real personal income excluding transfers of state $i$ at time $t, R \bar{P} I_{t}$ its cross-sectional mean at time $t$, while $n$ is the number of states.

Many scholars (Petrakos and Artelaris 2009; Petrakos, Rodriquez-Pose, and Rovolis 2005; Tortosa-Ausina, Perez, and Mas 2005) argue that the unweighted coefficient of variation is not an appropriate measure of income inequalities since it treats all spatial units as equal while ignoring their relative population sizes. For this reason, we prefer employing also a population-weighted coefficient of variation of per capita incomes as a second type of inequality measure:

$$
W C V_{t}=\frac{\sqrt{\sum_{i=1}^{n}\left(R P I_{i, t}-R \bar{P} I_{t}\right)^{2} *\left(p_{i t} / p_{N, t}\right)}}{R \bar{P} I_{t}}
$$

where $p_{i, t}$ is the population of state $\mathrm{i}$ at time $\mathrm{t}$ and $p_{N, t}$ is national population at time $\mathrm{t}$.

The third type of inequality measure that we employ is the one introduced by Theil (1967). The coefficient of variation is known to be relatively sensitive to the number of spatial units. In contrast, the merits of the Theil index such as its lower sensitivity to 
extreme values, being neither scale nor mean dependent makes it an interesting inequality measure. Therefore, additional to the coefficient of variation, we employ also the Theil index:

$$
\text { Theil }_{t}=\sum_{i=1}^{n} r p i_{i, t} \log \left(r p i_{i, t} / x_{i, t}\right)
$$

where $r p i$ is the gross income of a state relative to that of the national economy and $x$ is the population of a state relative to that of the U.S.

All the series used in this study are deflated using the 1982-1984 U.S. city average national consumer price index. The seasonality is adjusted using a "multiplicative ratio to moving average" technique, which is a tool that helps remove possible seasonality in the data by dividing the series into seasonal factors that are created using moving averages.

The evolution of income inequalities across states has been shown in Figure 1; it can easily be seen that disparities across states decrease until the late-1970s and then tend to follow an increasing pattern with an upward trend according to the unweighted and population-weighted coefficient of variation and a stationary process according to the Theil index. All three indices seem to follow synchronous oscillations that indicate the consistency across inequality measures.

In order to study the relationship between cross-sectional income disparities and business cycle, we consider the following regression model:

$$
\text { Ineq }_{t}=\alpha+\beta C Y C_{t}+\varepsilon_{t}
$$

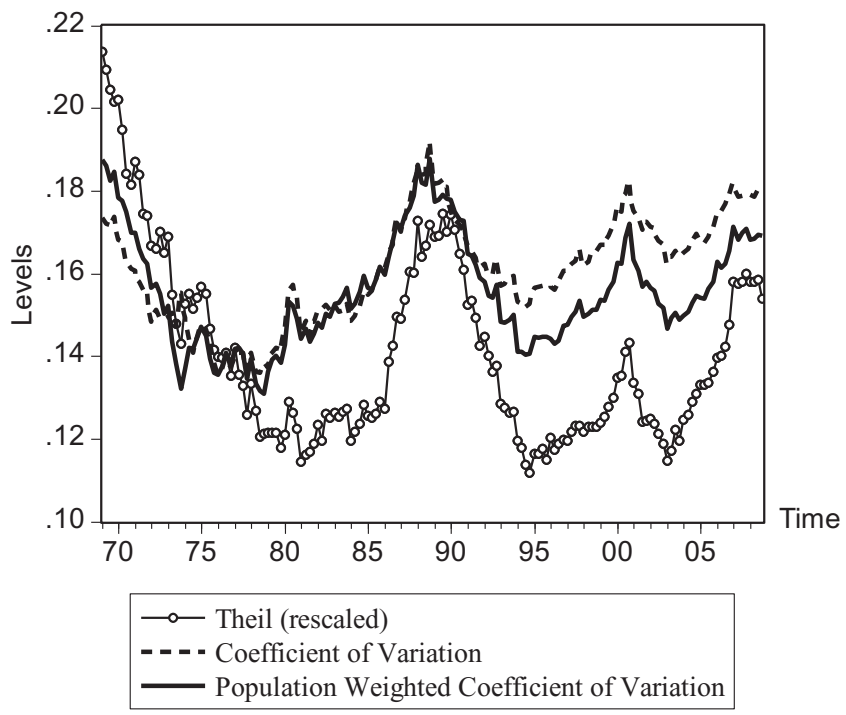

Figure 1. Evolution of Income Disparities Across States. 
Specifically, ineq represents the income inequalities across U.S. states and $C Y C_{t}$ is a measure of the national business cycle, which is derived by using a Hodrick-Prescott filtering to de-trend U.S. per capita real personal income net of current transfer receipts between 1969:1 and 2008:4. ${ }^{2}$

Clearly, a positive and significant estimate for $\beta$ would indicate that income disparities move in the same direction as the aggregate cycle, i.e., pro-cyclically. By contrast, a negative and significant $\beta$ implies that income inequalities move in the opposite direction to the aggregate cycle, i.e., anti-cyclically, or counter-cyclically.

With regard to the choice of our methodology, as seen in the regression model of equation (1), we prefer adopting time series regression rather than a panel data approach although the latter is known to have several merits. First, it incorporates the variability of observations both over time (temporally) and across spatial units (crosssectional), and, second, it gives the possibility of dealing with the known problems about endogeneity and causality. However, in our case, we think it is appropriate to adopt time series methodologies since the "national business cycle" variable is unique for all states and, therefore, includes no variation across spatial units. Furthermore, time series properties of regional inequalities have remained largely uncovered in the literature, which makes it an interesting methodology per se.

Before effectively obtaining the estimates, however, a couple of crucial issues must be addressed. First, for the business cycle estimation, a number of filtering techniques are available in the literature, among many others those proposed by Hodrick and Prescott (1997) (HP), and by Christiano and Fitzgerald (2000) (CF). In Table 1, we compare the CF and HP cycles for the aggregate economy and check their ability to match the official timing provided by the National Bureau of Economic Research (NBER).

Although the two filters give similar results, in what follows we adopt the HP filter due to its simplicity and widespread use in the literature. Denoting income at time $t$ with $y_{t}$, the HP filter minimizes in $\tau_{t}$ the following expression:

TABle 1. NBER CyCles AND TuRning PoInTs IMPlied By Different Filter.

\begin{tabular}{lccclccc}
\hline & NBER & HP & CF & & NBER & HP & CF \\
\hline Peak & $1969-4$ & $1969-3$ & $1969-3$ & Trough & & $1986-4$ & $1987-4$ \\
Trough & $1970-4$ & $1970-4$ & $1971-1$ & Peak & $1990-3$ & $1989-1$ & $1990-2$ \\
Peak & $1973-4$ & $1973-4$ & $1973-3$ & Trough & $1991-1$ & $1991-4$ & $1991-3$ \\
Trough & $1975-1$ & $1975-2$ & $1975-3$ & Peak & & $1994-4$ & $1994-3$ \\
Peak & $1980-1$ & $1979-1$ & $1979-1$ & Trough & & $1995-4$ & $1997-2$ \\
Trough & $1980-3$ & & & Peak & $2001-1$ & $2000-1$ & $2000-3$ \\
Peak & $1981-3$ & & & Trough & $2001-4$ & $2003-1$ & $2003-2$ \\
Trough & $1982-4$ & $1982-4$ & $1982-4$ & Peak & $2007-4$ & $2007-2$ & $2007-3$ \\
Peak & & $1984-3$ & $1984-3$ & & & & \\
\hline
\end{tabular}




$$
\min \sum_{t=1}^{T}\left(y_{t}-\tau_{t}\right)^{2}+\lambda \sum_{t=2}^{T-1}\left[\left(\tau_{t+1}-\tau_{t}\right)-\left(\tau_{t}-\tau_{t-1}\right)\right]^{2}
$$

where $\lambda$ is a penalty parameter that captures the smoothness of the trend $\tau_{t}$. As recommended by Hodrick and Prescott (1997) for quarterly data, we set $\lambda=1600$.

A second important issue in time series analysis concerns the stationarity properties of the variables that guarantee valid regression inference. In order to check this out, we implement the Augmented Dickey Fuller (ADF) test (Dickey and Fuller 1979) for each variable. We determine the optimal lag length for the ADF regressions by choosing the number of lags that minimizes the Akaike information criterion. ${ }^{3}$ Table 2 summarizes the results. We observe that all measures of cross-sectional income disparities follow a nonstationary, I(1), process. So, in order to introduce this variable in the regression model of equation (1), we make them stationary by applying the HP filter; de-trending the disparities enables us to observe the increase/ decrease in disparities, not in absolute terms, but relative to its trend. The de-trended disparities (labeled as CVHP, WCVHP, and TheilHP for the unweighted and weighted coefficient of variation and the Theil index respectively) and the business cycle variable $(C Y C)$ exhibit mean reversion over time and therefore follow an $\mathrm{I}(0)$ stationary process.

We can now turn to the regression estimates, using CVHP, WCVHP, and TheilHP as dependent variables. It should be observed, however, that ordinary least squares estimates suffer from a serial correlation problem. In order to address this, we allow for first order autoregressive errors and, in this way, get rid of the serial correlation. Doing this, no more evidence of serial correlation is found via Breusch-Godfrey Lagrange multiplier test (Breusch 1978; Godfrey 1978) using up to four quarters lag length. In actual facts, the estimated model is

TABle 2. ADF Test Results.

\begin{tabular}{lccc}
\hline Variable & ADF statistic & Optimal lag length & Process \\
\hline CV & -1.08 & 1 & $\mathrm{I}(1)$ \\
WCV & -1.50 & 1 & $\mathrm{I}(1)$ \\
Theil & -2.52 & 5 & $\mathrm{I}(1)$ \\
CVHP & $-4.26 * * *$ & 1 & $\mathrm{I}(0)$ \\
WCVHP & $-4.44 * * *$ & 1 & $\mathrm{I}(0)$ \\
TheilHP & $-3.86^{* * *}$ & 1 & $\mathrm{I}(0)$ \\
CYC & $-5.13^{* * *}$ & 4 & $\mathrm{I}(0)$ \\
\hline
\end{tabular}

Notes: Significance levels: * 10\%, ** 5\%,*** $1 \%$.

Optimal lag length is chosen using Akaike information criterion. 


$$
\left\{\begin{array}{l}
\text { Ineq }_{t}=\alpha+\beta C Y C_{t}+\varepsilon_{t} \\
\varepsilon_{t}=\rho \varepsilon_{t-1}+u_{t}
\end{array}\right.
$$

That yields the transformed model:

$$
\text { Ineq }_{t}=\alpha(1-\rho)+\rho \text { Ineq }_{t-1}+\beta\left(C Y C_{t}-\rho C Y C_{t-1}\right)+u_{t}
$$

The serial correlation parameter $\rho$ and the coefficient $\beta$ are simultaneously estimated using the Levenberg-Marquardt nonlinear least squares algorithm (Levenberg 1944; Marquardt 1963). ${ }^{4}$

The regression results are summarized in Table 3 from which it is immediate to note that over the entire period the estimate of $\beta$ is not significantly different from zero in all regressions. This result might be due to a change in the relationship between the business cycle and income disparities over the period of analysis brought in by political and socioeconomic transformations in the U.S. Therefore, we think it might be useful to split the period of analysis into subperiods and investigate the evolution of the relationship between the business cycle and income disparities. In order to do so, we split the period of analysis into three subperiods: the first runs from 1969:1 to 1982:4 (national trough), the second from 1983:1 to 1991:4 (national trough), and the third from 1992:1 to 2008:4.

In order to justify the choice of the subperiods, we provide a brief account of economic circumstances that might have shaped the cyclical behavior of disparities across states during each of these specific periods. For the first subperiod, between the late 1960s and early 1980s, it is known that capital and labor diffuses from developed areas to low income (peripheral) locations due to lower labor and land costs, higher profit rate opportunities for firms, less unionization, and better climate (Fan and Casetti 1994). The pace of the factor flows is known to be faster during the national boom times, fostering economic growth in poorer states and accelerating their convergence to richer ones. By contrast, during slumps it is likely that the flow of factors stagnates which, in turn, stops the convergence process. Consequently, it is plausible to believe that inequalities across states follow a counter-cyclical pattern during this period, decreasing during expansions and increasing during recessions.

Second, the 1980s is recognized as a period of transition in which factor movements start changing their direction and tend to flow into the developed states that specialize in high-tech and service industries, which became the new leading industries (Fan and Casetti 1994). The leading role of high-tech industries occurred probably as a consequence of the transformation of the U.S. economy toward a knowledge-based "new economy" (DeVol et al. 1999) and due to an increase in international competition, such as the rise of newly industrializing economies (China and India). Quite naturally, it is hard to assume that the change in the direction of factor flows happens suddenly. By contrast, it is likely that a period of smooth adjustment takes place. Consequently, one may expect to observe an ambiguous pattern, due to a combination of both pro- and counter-cyclical disparities during this period. 
TABLE 3. REgRESSION RESUltS.

\begin{tabular}{|c|c|c|c|c|}
\hline \multirow{2}{*}{$\begin{array}{l}\text { Dependent variable: } \\
\text { Coefficients }\end{array}$} & \multicolumn{4}{|c|}{ Population-weighted coefficient of variation (WCVHP) } \\
\hline & 1969-2008 & $1969-1983$ & 1983-1992 & $1992-2008$ \\
\hline$\alpha$ & $-4.37 \mathrm{E}-05$ & -0.0003 & 0.001 & -0.0002 \\
\hline$\beta$ & $-1.88 \mathrm{E}-07$ & $-1.18 \mathrm{E}-05 * * *$ & $-3.96 \mathrm{E}-06$ & $9.71 \mathrm{E}-06 * * *$ \\
\hline Autoregressive error & $0.73 * * *$ & $0.68 * * *$ & $0.78 * * *$ & $0.65 * * *$ \\
\hline R-squared & 0.53 & 0.53 & 0.53 & 0.70 \\
\hline White & $14.42 * * *$ & $1.54 *$ & $1.45^{*}$ & $12.06^{* * *}$ \\
\hline Breusch-Godfrey & 0.008 & 0.34 & 1.19 & 0.15 \\
\hline F-stat & $87.87 * * *$ & $29.59 * * *$ & $18.86 * * *$ & $75.63 * * *$ \\
\hline Log-likelihood & 698.80 & 243.81 & 156.85 & 315.25 \\
\hline Dependent variable: & \multicolumn{4}{|c|}{ Theil index (TheilHP) } \\
\hline Coefficients & 1969-2008 & 1969-1983 & 1983-1992 & $1992-2008$ \\
\hline$\alpha$ & $-9.85 \mathrm{E}-06$ & $-4.87 \mathrm{E}-06$ & $1.27 \mathrm{E}-05$ & $-2.28 \mathrm{E}-05$ \\
\hline$\beta$ & $6.80 \mathrm{E}-08$ & $-4.02 \mathrm{E}-07 * * *$ & $1.09 \mathrm{E}-07$ & $5.48 \mathrm{E}-07 * * *$ \\
\hline Autoregressive error & $0.74 * * *$ & $0.43 * * *$ & $0.81 * * *$ & $0.70 * * *$ \\
\hline R-squared & 0.56 & 0.33 & 0.67 & 0.76 \\
\hline White & $7.42 * *$ & 0.64 & $2.36^{*}$ & $11.15^{* * *}$ \\
\hline Breusch-Godfrey & 0.31 & $1.22 *$ & $2.86^{* *}$ & 0.006 \\
\hline F-stat & $99.57 * * *$ & $13.08 * * *$ & $33.39 * * *$ & $105.31 * * *$ \\
\hline Log-likelihood & 1157.03 & 400.79 & 258.29 & 519.49 \\
\hline
\end{tabular}

Dependent variable:

Unweighted coefficient of variation (CVHP)

\begin{tabular}{lcccc} 
Coefficients & $1969-2008$ & $1969-1983$ & $1983-1992$ & $1992-2008$ \\
\hline$\alpha$ & $-1.36 \mathrm{E}-05$ & 0.0002 & $-9.56 \mathrm{E}-05$ & $-5.64 \mathrm{E}-05$ \\
$\beta$ & $9.11 \mathrm{E}-07$ & $-4.11 \mathrm{E}-06$ & $-9.02 \mathrm{E}-06$ & $6.99 \mathrm{E}-06 * * *$ \\
Autoregressive error & $0.73^{* * *}$ & $0.60^{* * *}$ & $0.91^{* * *}$ & $0.65^{* * *}$ \\
R-squared & 0.55 & 0.34 & 0.72 & 0.67 \\
White & $7.36^{* *}$ & $1.36^{*}$ & 2.88 & $9.91^{* * *}$ \\
Breusch-Godfrey & 0.12 & 0.32 & 0.33 & 0.17 \\
F-stat & $97.13^{* * *}$ & $13.49^{* * *}$ & $43.15^{* * *}$ & $67.22^{* * *}$ \\
Log-likelihood & 714.80 & 241.79 & 160.38 & 326.93 \\
\hline
\end{tabular}

Notes: Significance levels: $* 10 \%, * * 5 \%, * * * 1 \%$

White is the White Heteroskedasticity test. In case of heteroskedasticity, White heteroskedasticity robust standard errors are used. Breusch-Godfrey is the BreuschGodfrey LM test for serial correlation. 
For the most recent subperiod, after the early 1990s, capital and labor that flows into states that specialize in high-tech industries now clearly favors the developed states. These factor flows are known to be faster during expansions and slower during recessions. Consistent with this pattern, inequalities across states are expected to enlarge during the periods of expansion and diminish in times of recession.

Columns 2, 3, and 4 of Table 3 report the corresponding estimates of the parameter $\beta$ in the three subperiods. The estimated $\beta$ coefficient for the first subperiod (19691983 ) is negative and significant (at 1 percent level) for the regressions that employ the population-weighted coefficient of variation and the Theil index as the dependent variables and insignificant for the regression that adopts the unweighted coefficient of variation as the dependent variable. Thereby, the results suggest, in general, the existence of an anti-cyclical behavior for the cross-sectional disparities during this period.

For the second subperiod (1983-1992), which has been recognized as a transition phase, no evidence of anti- or pro-cyclical disparities has been found. This is most probably due to the fact that pro- and anti-cyclical disparities coexist during this period and, possibly, cancel out each other's effect.

For the most recent subperiod (1992-2008) there exists strong evidence for procyclical disparities since $\beta$ is significant at 1 percent level and positive for all regressions. Hence, it appears that income disparities have turned from being anti-cyclical to pro-cyclical over time and now tend to co-move with the cycle of the aggregate economy.

In addition to the model (1), we consider an alternative regression specification to check the robustness of our results and regress the first differences of our measures of cross-sectional income disparities on the growth rate of the aggregate economy.

Table 4, which reports the regression estimates, confirms the picture drawn above. No significant relationship between the growth rate of the economy and income disparities is found over the entire period. The $\beta$ coefficient is negative and significant before 1983, insignificant between 1983 and 1992 and strongly significant (at 1 percent level) and positive afterward.

To sum up, using two alternative regression specifications and three different inequality measures, we find that income disparities across U.S. states exhibit an anti-cyclical pattern until the early 1980s, ambiguous behavior during a transition phase from 1983 to 1992, and a pro-cyclical behavior afterward.

As anticipated, one of the most plausible explanations of the detected short-run patterns of regional inequalities is the change in the direction of factor flows across states. Before the 1980s, capital and labor diffuse from developed states to poorer ones. These flows are known to accelerate during national expansion times, which stimulate the economic growth and catch-up process for poorer states. Since these flows stagnate during recessions, inequalities tend to increase. Hence, income inequalities across states follow a counter-cyclical pattern. By contrast, after the early $1990 \mathrm{~s}$, factors tend to flow into the developed states that specialize in service and high-tech industries. These flows that accelerate during the times of expansion favor the economic growth 
Table 4. Alternative Regression Results.

\begin{tabular}{|c|c|c|c|c|}
\hline \multirow{2}{*}{$\begin{array}{l}\text { Dependent variable: } \\
\text { Coefficients }\end{array}$} & \multicolumn{4}{|c|}{ Population-weighted coefficient of variation } \\
\hline & 1969-2008 & 1969-1983 & 1983-1992 & 1992-2008 \\
\hline$\alpha$ & $-5.35 \mathrm{E}-05$ & -0.0003 & $9.74 \mathrm{E}-05$ & -0.0002 \\
\hline$\beta$ & -0.05 & $-0.45 * * *$ & 0.09 & $0.29 * * *$ \\
\hline R-squared & 0.003 & 0.30 & 0.007 & 0.16 \\
\hline White & $31.42 * * *$ & $1.12 * * *$ & 2.90 & 1.93 \\
\hline Breusch-Godfrey & 0.07 & 0.16 & $1.02 * * *$ & 0.02 \\
\hline F-stat & 0.54 & $22.26^{* * *}$ & 0.25 & $12.84 * * *$ \\
\hline Log-likelihood & 675.50 & 237.78 & 150.85 & 305.96 \\
\hline
\end{tabular}

Dependent variable:

Theil index

\begin{tabular}{lcccc} 
Coefficients & $1969-2008$ & $1969-1983$ & $1983-1992$ & $1992-2008$ \\
\hline$\alpha$ & $-1.54 \mathrm{E}-05$ & $-5.13 \mathrm{E}-05$ & $1.70 \mathrm{E}-07$ & $-1.07 \mathrm{E}-05$ \\
$\beta$ & -0.0008 & $-0.021^{* * *}$ & 0.011 & $0.014^{* * *}$ \\
R-squared & 0.0003 & 0.20 & 0.03 & 0.14 \\
White & $3.19^{* * *}$ & $1.49^{* * *}$ & 0.16 & 0.23 \\
Breusch-Godfrey & 0.20 & 0.13 & $1.06^{* * *}$ & 0.60 \\
F-stat & 0.04 & $13.16^{* * *}$ & 1.143 & $10.82^{* * *}$ \\
Log-likelihood & 1131.80 & 391.41 & 253.01 & 507.96 \\
\hline Dependent variable: & \multicolumn{5}{c}{ Unweighted coefficient of variation } \\
\cline { 3 - 5 } Coefficients & $1969-2008$ & $1969-1983$ & $1983-1992$ & $1992-2008$ \\
\hline \multirow{2}{*}{$\beta$} & $4.81 \mathrm{E}-05$ & -0.0002 & 0.0002 & $-3.12 \mathrm{E}-06$ \\
$\beta$ & -0.005 & $-0.24 * *$ & 0.026 & $0.21^{* * *}$ \\
R-squared & 0.00004 & 0.10 & 0.0007 & 0.13 \\
White & $14.00^{* *}$ & $1.37^{* * * * *}$ & $1.99 * * * *$ & $2.24 *$ \\
Breusch-Godfrey & 0.08 & 0.19 & 0.02 & 0.18 \\
F-stat & 0.006 & $5.68^{* *}$ & 0.03 & $9.99^{* * *}$ \\
Log-likelihood & 693.99 & 234.93 & 153.93 & 318.95 \\
\hline
\end{tabular}

Notes: Significance levels: * 10\%, ** 5\%,*** $1 \%$.

White is the White Heteroskedasticity test. In case of heteroskedasticity, White heteroskedasticity robust standard errors are used. Breusch-Godfrey is the BreuschGodfrey LM test for serial correlation. 
in developed states that increases the gap between rich and poor states. Conversely, since the pace of these factor flows slows down during recessions, income inequalities tend to decrease. In total, regional disparities follow a pro-cyclical pattern.

Finally, our results have important implications for regional economic policy. First, we have understood that the evolution of regional inequalities is partially predictable using the performance of the aggregate economy (Petrakos and Saratsis 2000). Second, after the early 1990s, regional policy in the U.S. is likely to be more important during booms than slumps since inequalities tend to enlarge during the times of expansion (Chatterji and Dewhurst 1996). Lastly, we suggest that dealing with income inequalities in the U.S. is harder than initially understood since the economic growth of the aggregate economy, which is one of the primary objectives of policy makers, persistently regenerates inequalities regardless of how other factors affect the inequalities (Petrakos, Rodriquez-Pose, and Rovolis 2005; Petrakos and Saratsis 2000).

\section{Are There Meaningful State-Level Cycles?}

After having characterized the short-run behavior of cross-sectional income disparities, we now start investigating the short-run dynamics underneath their evolution and try to establish whether it could be explained by differences in the timing with which the business cycle is felt across states or it could instead be motivated by amplitude differences across local cyclical swings. Before doing so, it is, however, useful to understand whether there exist meaningful state-level cycles with different characteristics in timing and amplitudes. Clearly, if there were no sizable differences in timing or amplitudes across state cycles, it would be unlikely that the two mechanisms could actually play any important role in the evolution of the disparities. To investigate the differences in timing and amplitudes, we first detect the turning points in state-level cycles and then evaluate the size of such differences using several measures commonly adopted in the literature.

Turning points detection. Several methodologies for detecting turning points have been put forward in the literature (Bry and Boschan 1971; Harding and Pagan 2002). The early literature focused on how to accurately replicate the NBER's dates using single series. Bry and Boschan (1971) first documented the formal algorithm that aims at finding specific phases and cycles in the economic series. Harding and Pagan (2002) reorganized the algorithm and modified it for quarterly data.

It must be emphasized that although much effort has been put on dating business cycles at the national level, little work has been done at the regional or state level (e.g., Hall and McDermott 2004; Owyang, Piger, and Wall 2005). So, apart from representing the first step in our investigation on the short-run dynamics underneath the evolution of income disparities, dating the state-level cycles represents an interesting issue per se. To do so, we employ the Bry-Boschan Quarterly algorithm to detect turning points for the U.S. aggregate cycle as well as for 48 state-level cycles using HP de-trended (logarithm of) per capita real personal income (excluding transfers) 
between 1969 and 2008. The main principles of the Bry-Boschan algorithm require that any selected cycle, expansion, and recession are characterized by an adequate duration. The algorithm is therefore designed to, first, detect the local minima and maxima in the series and, second, impose restrictions to ensure the duration of the phases. (See Appendix A for details of the algorithm).

Results from the application of the Bry-Boschan algorithm to the U.S. States data are presented in Table 5. At a first glance, it can be observed that while until the mid-1980s, state-level turning points are concentrated around the national turning points, by contrast, these turning points are rather dispersed afterward. This implies a tendency for state cycles to become less synchronized with respect to the U.S. cycle. In the next subsection, we deepen these findings by quantifying the level of synchronization using several measures commonly adopted in the literature.

Cycle synchronization among states. A growing body of literature investigates whether national, or regional, cycles tend to synchronize with each other and the economic factors behind the observed patterns. A first strand of this literature concentrates on the co-movement of the cycles. For instance, Fatás (1997) studies the co-movement among European countries, Artis and Zhang (1999) among Organisation for Economic Co-operation and Development (OECD) countries, Montoya and Haan (2007) among European regions, and Carlino and Sill (2001) among U.S. regions. However, in only a small proportion of cases the authors detected the cycle turning points and subsequently used this piece of information when assessing the level of synchronization among cycles (Hall and McDermott 2004; Owyang, Piger, and Wall 2005). In line with these fewer works, we think that the (dis)similarities in the timing of the turning points may provide useful information about the synchronization of the cycles. In this section, therefore, we employ several descriptive statistics to explore the variation in timing across the cycles of U.S. states.

Recently, two popular measures of synchronization have been developed. These are the concordance index and the diffusion index. Owyang, Piger, and Wall (2005) relied on the first index to evaluate the degree of synchronization between U.S. states and the aggregate economy. Similarly, Hall and McDermott (2004) used the same index to analyze the degree of synchronization among regions of New Zealand. Artis, Marcellino, and Proietti (2003) instead used both indexes to evaluate synchronization within the Euro area. Specifically, the concordance index measures the percentage of time in which two economies are in the same business cycle phase. In equation (2), $I$ measures the concordance between the cycles of economies $i$ and $j$ over a period of $T$ instants:

$$
I=\frac{1}{T} \sum_{t=1}^{T}\left[S_{i, t} S_{j, t}+\left(1-S_{i, t}\right)\left(1-S_{j, t}\right)\right]
$$

where $S$ is a binary variable that takes on value 1 when an economy is in recession and value 0 when it is in an expansion. The index thus ranges between 1 and 0 ; when $I$ is 
INCOME DISPARITIES AND REGIONAL CYCLE SYNCHRONIZATION 307

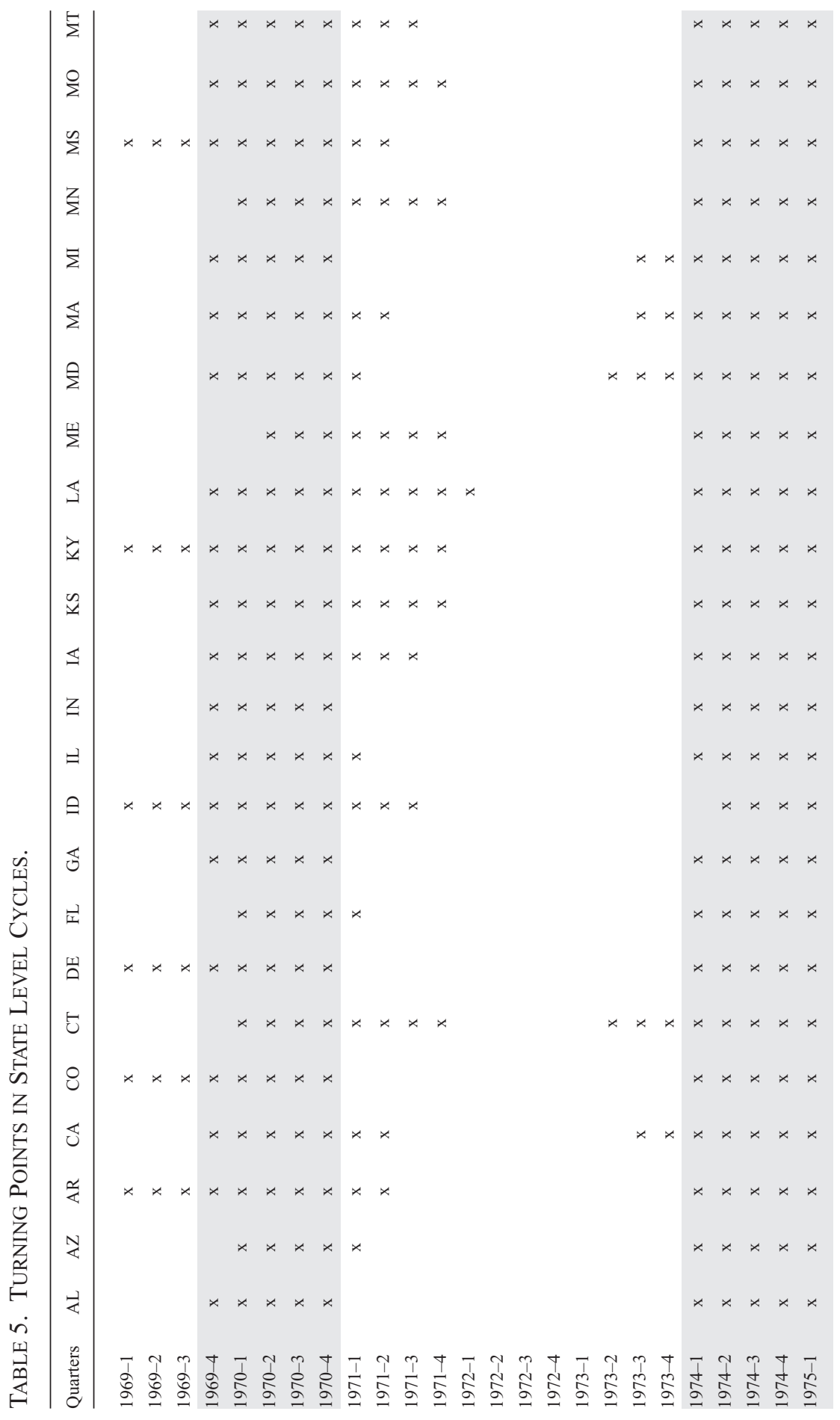


308 GROWTH AND CHANGE, JUNE 2014

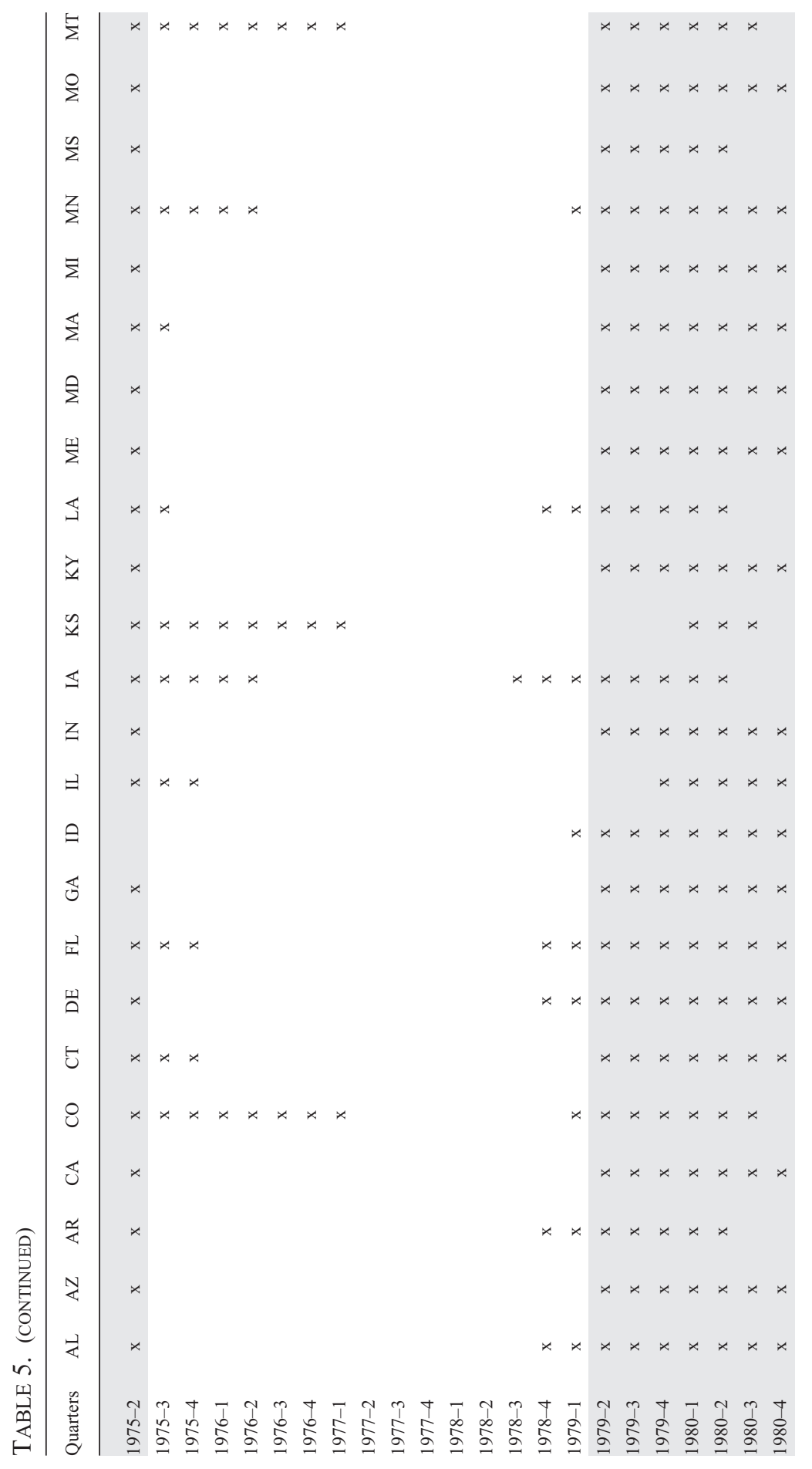




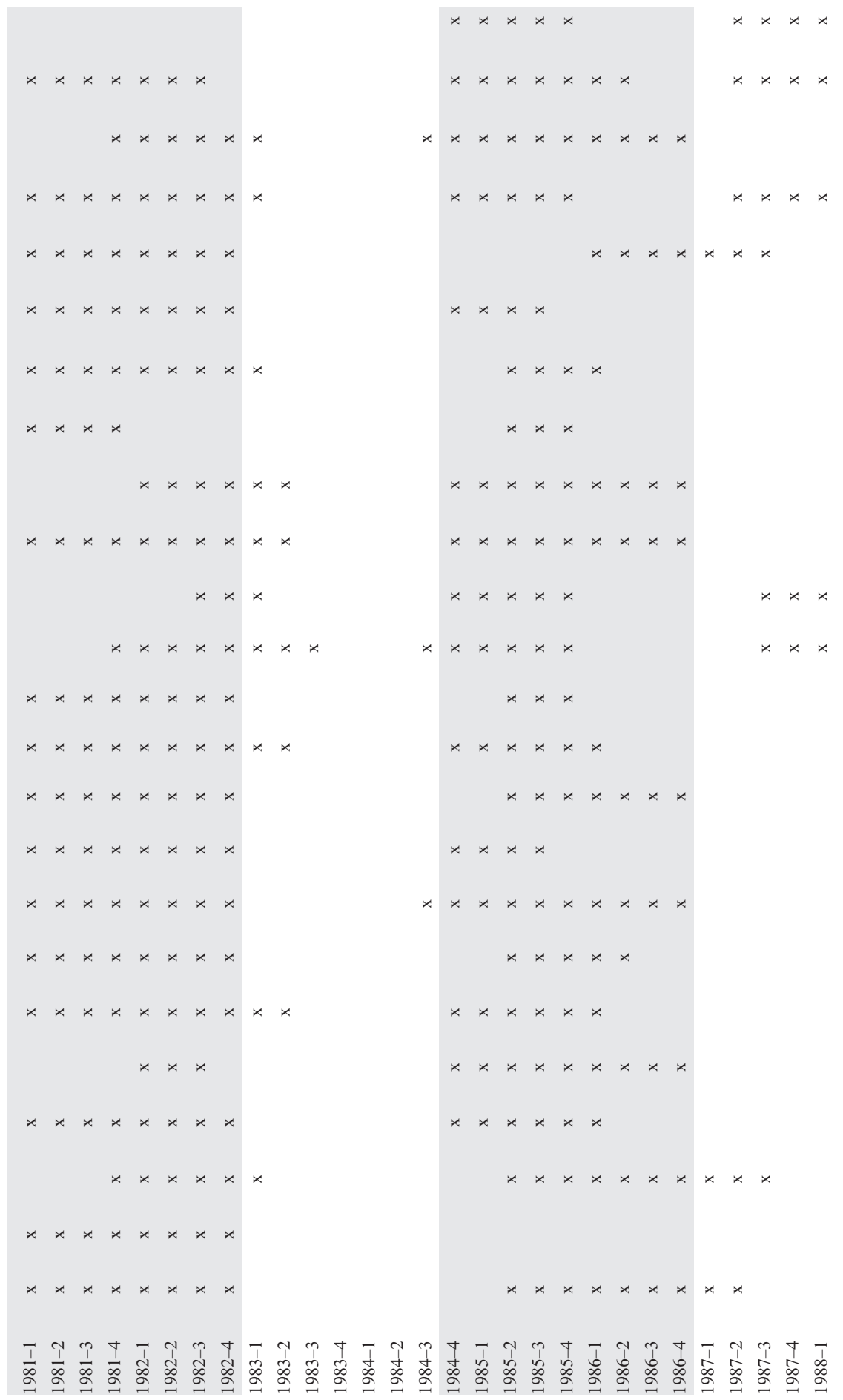


310 GROWTH AND CHANGE, JUNE 2014

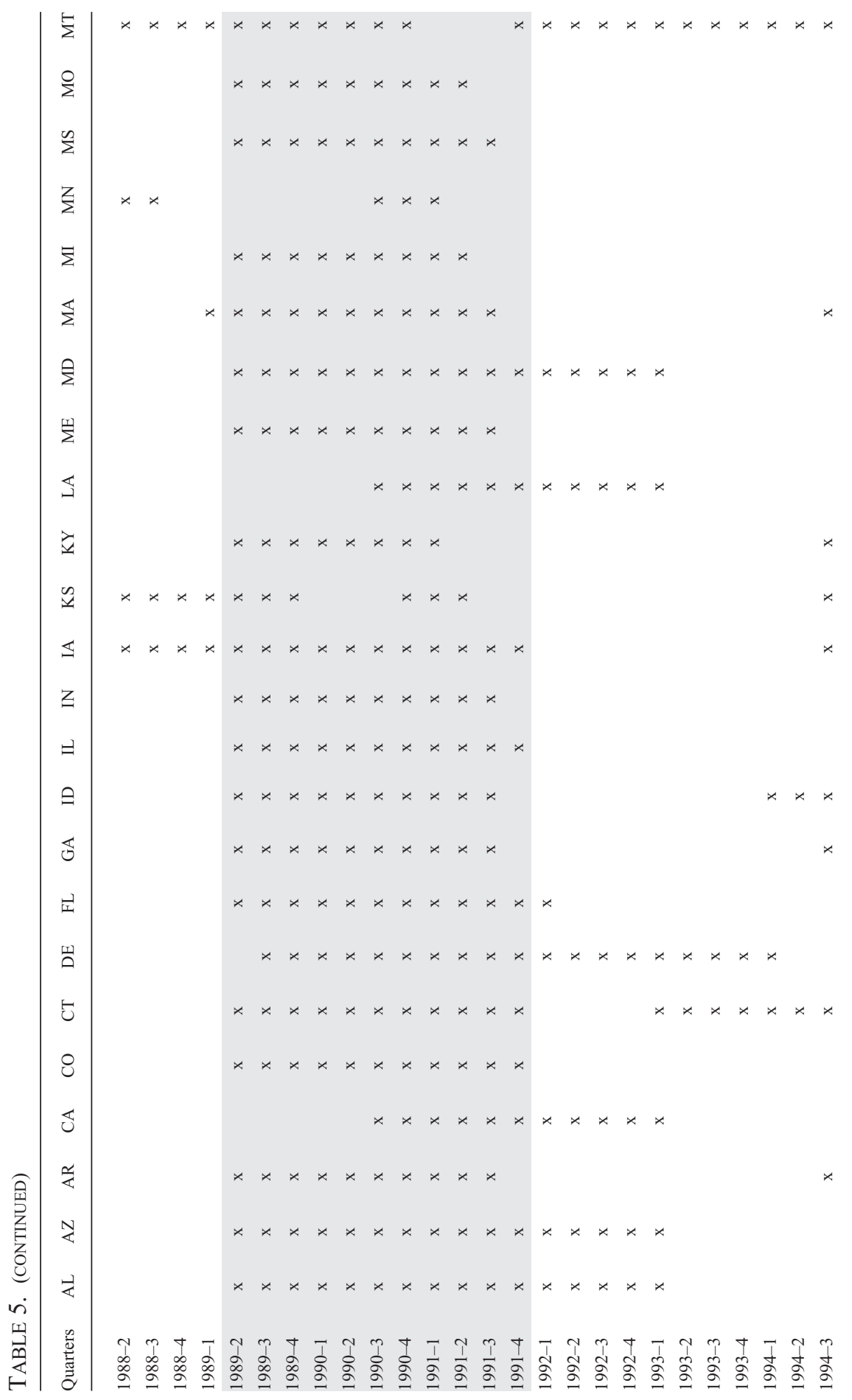


INCOME DISPARITIES AND REGIONAL CYCLE SYNCHRONIZATION 311

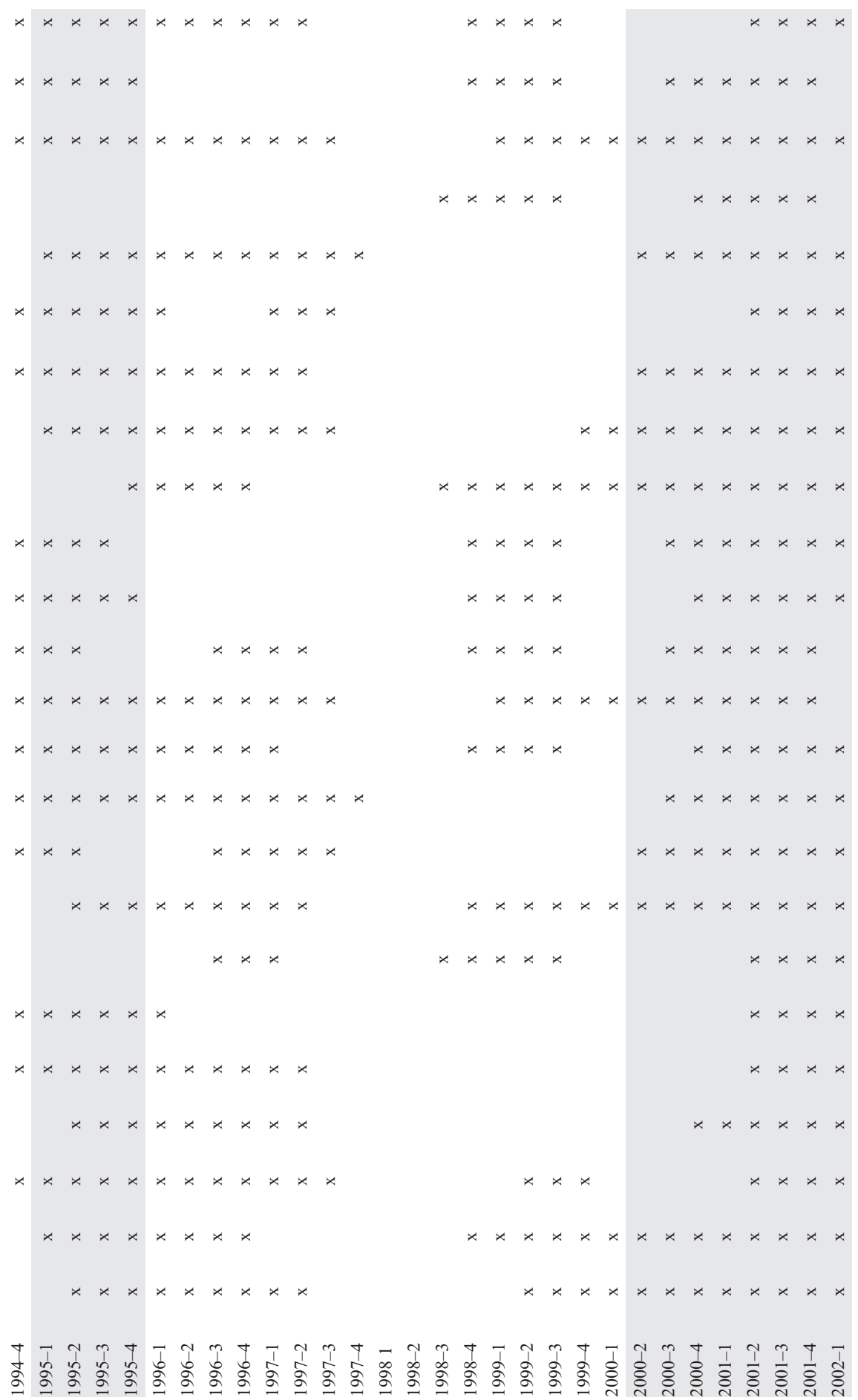


312 GROWTH AND CHANGE, JUNE 2014

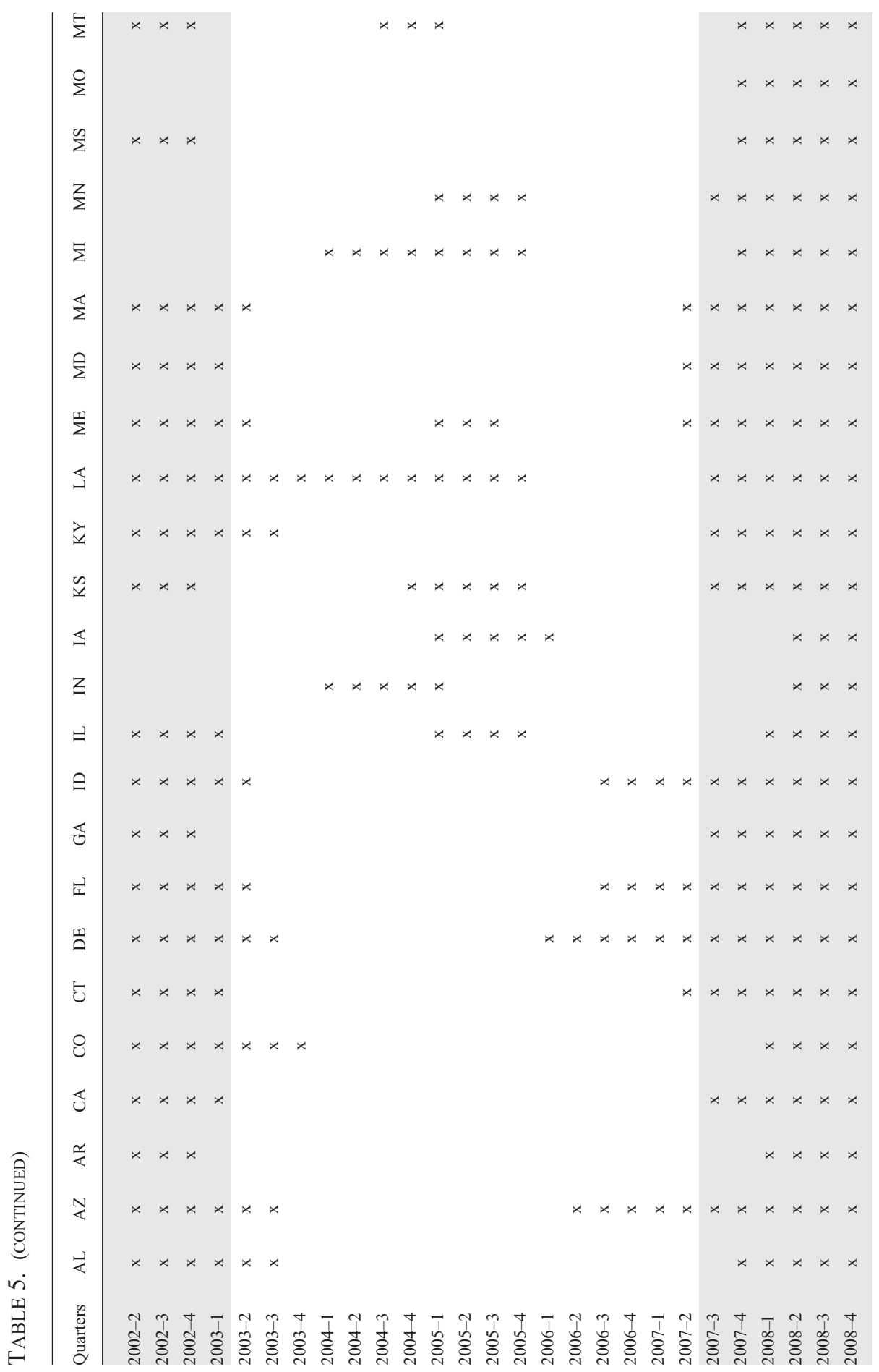


INCOME DISPARITIES AND REGIONAL CYCLE SYNCHRONIZATION 313

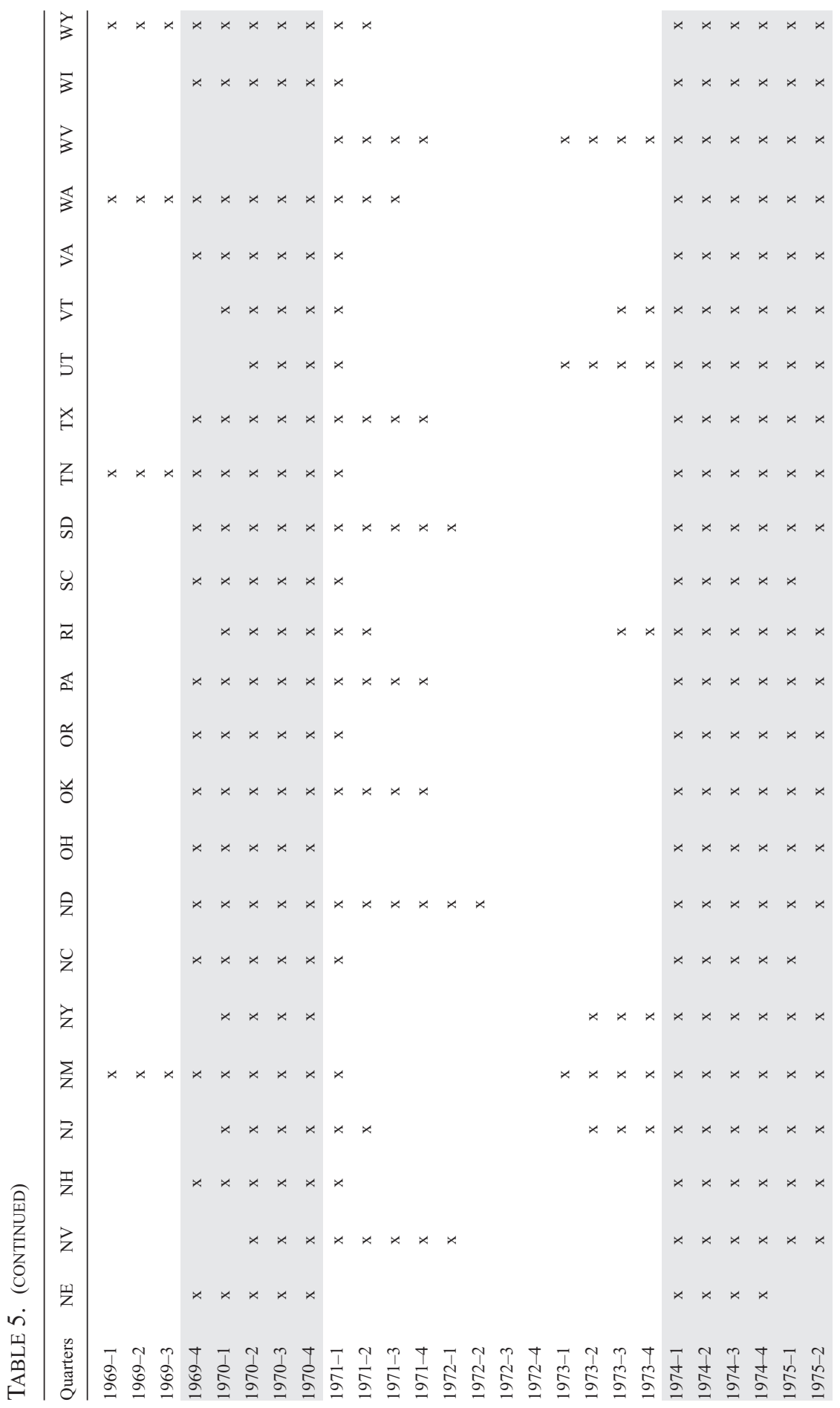


314 GROWTH AND CHANGE, JUNE 2014

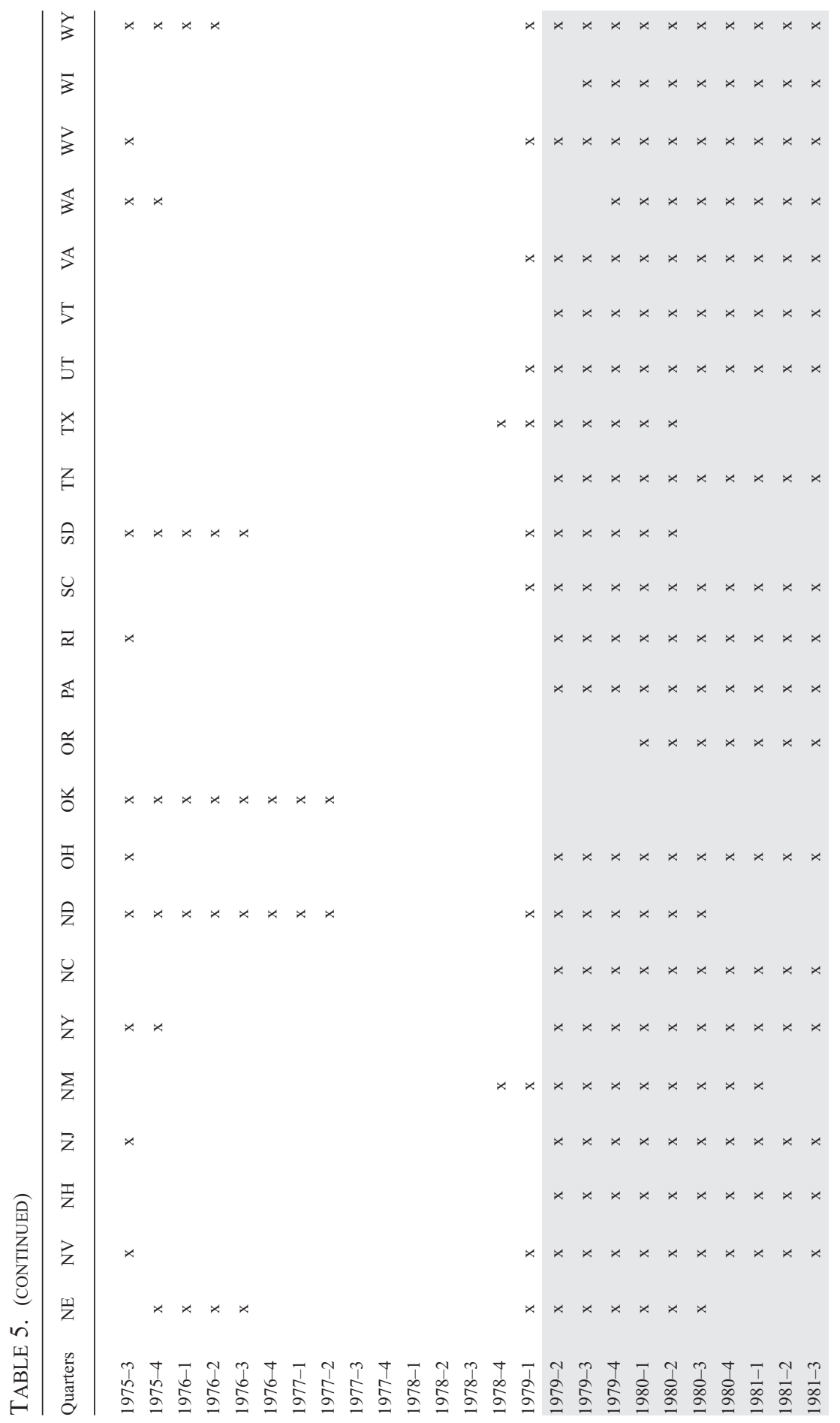


INCOME DISPARITIES AND REGIONAL CYCLE SYNCHRONIZATION 315

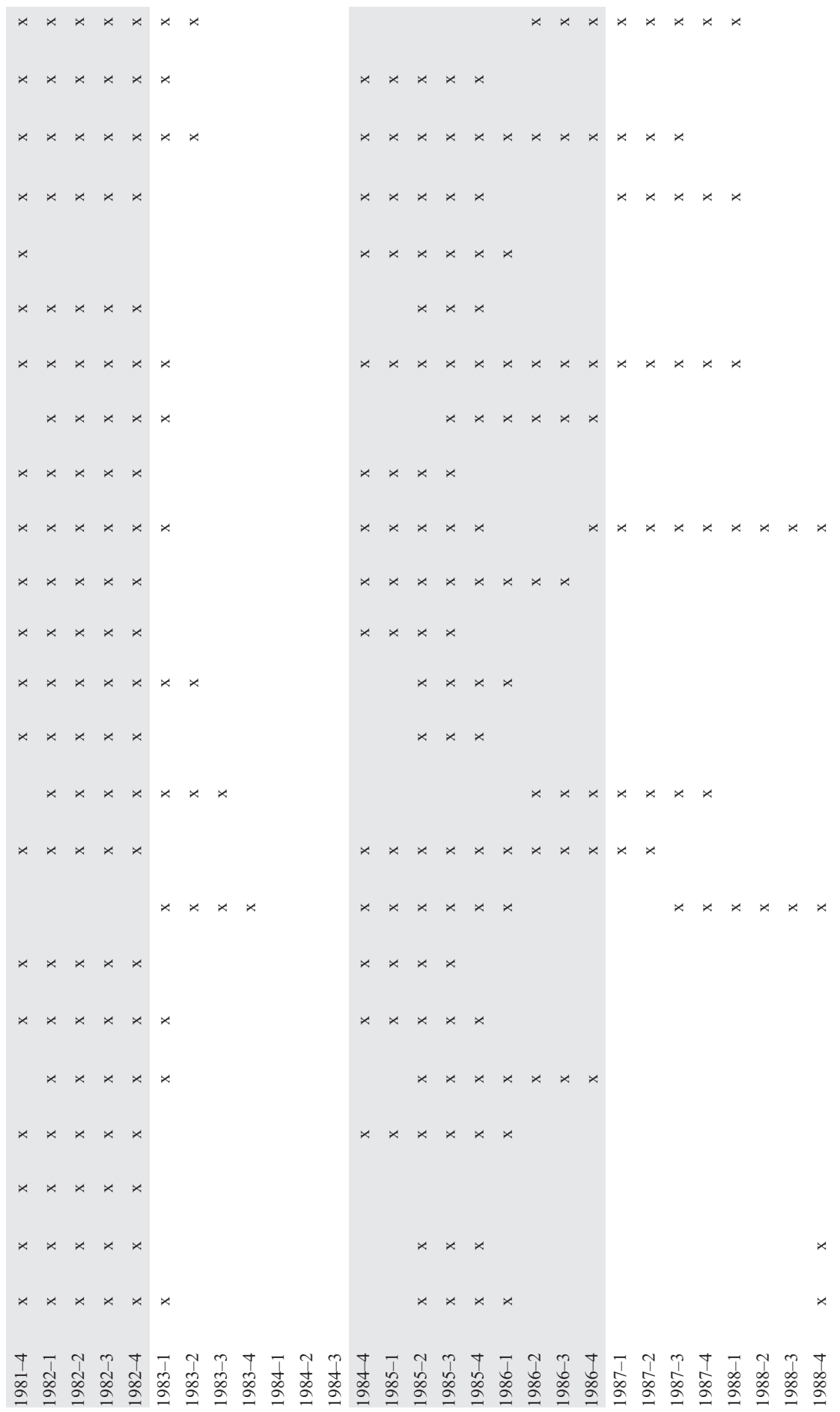




\section{GROWTH AND CHANGE, JUNE 2014}

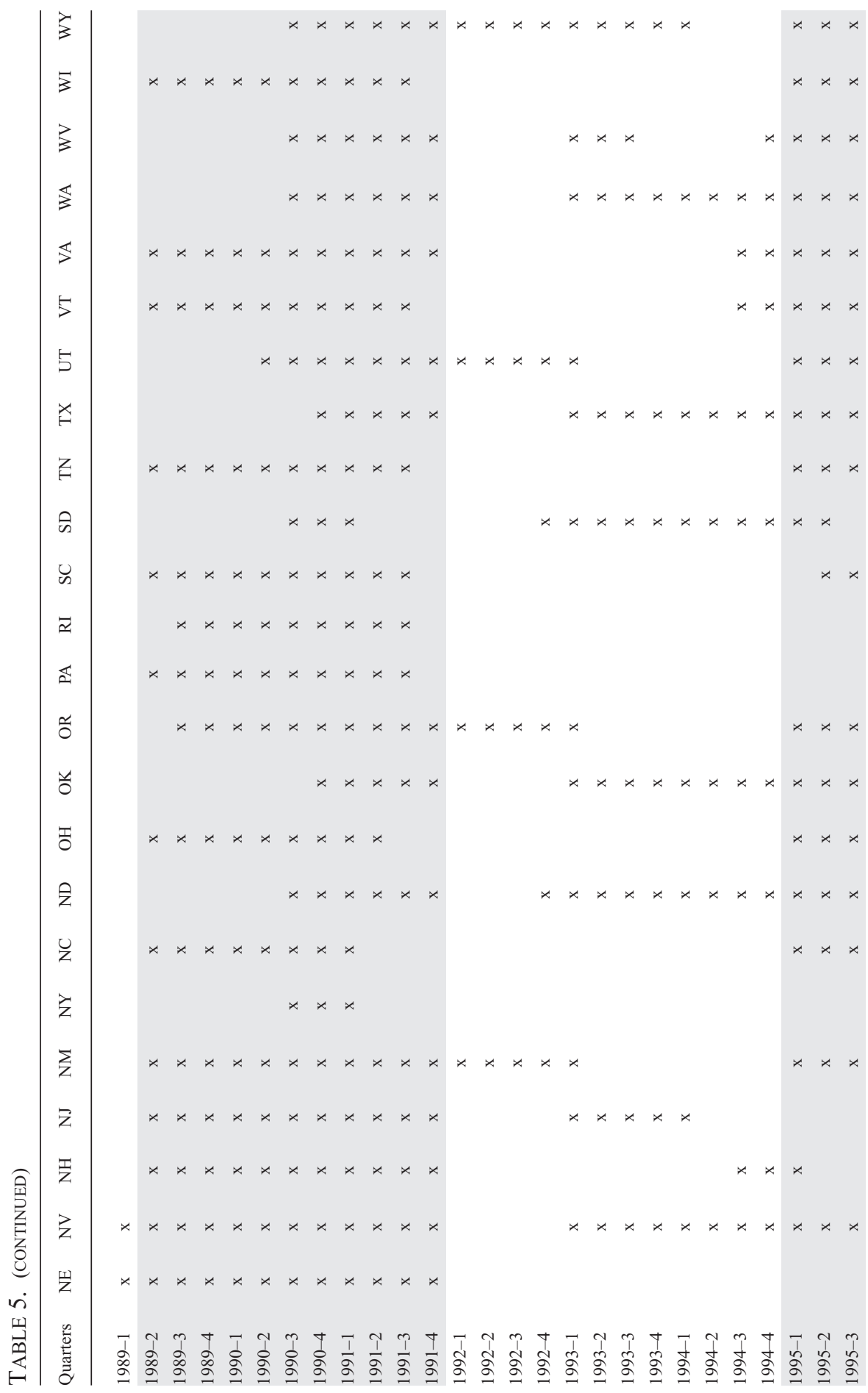


INCOME DISPARITIES AND REGIONAL CYCLE SYNCHRONIZATION 317

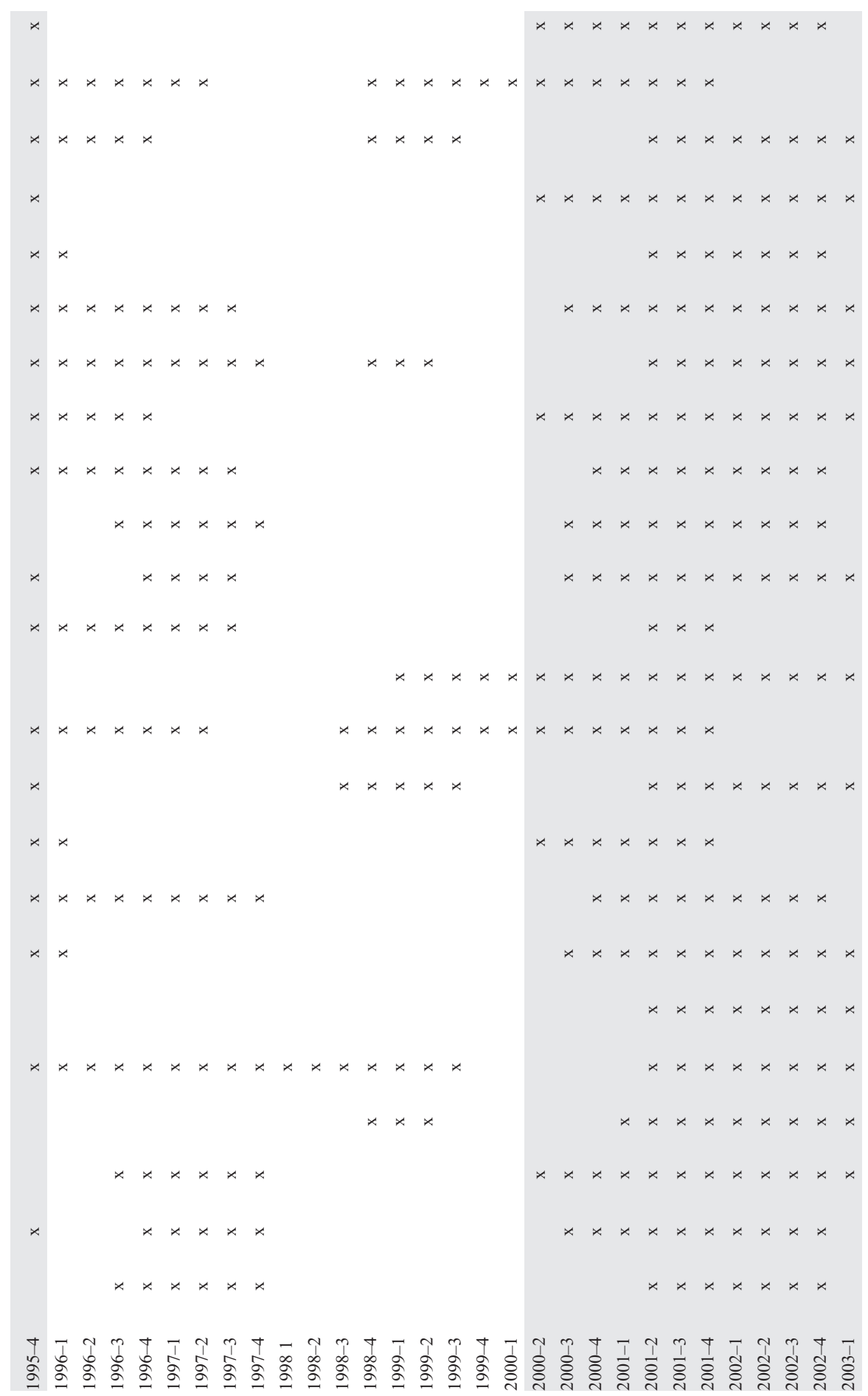


318 GROWTH AND CHANGE, JUNE 2014

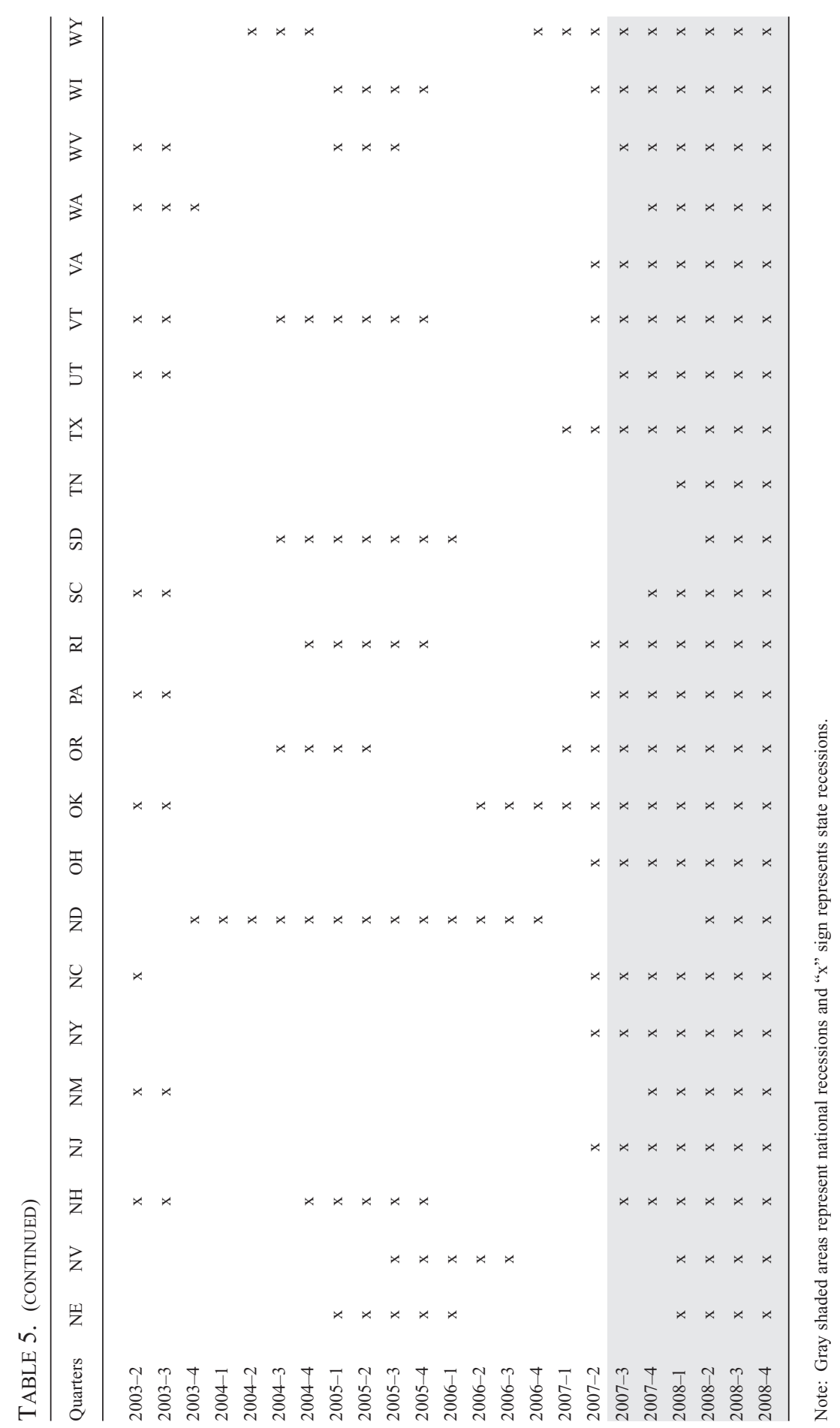


equal to 1 there is perfect synchronization between economies, i.e., $i$ and $j$ are in the same cycle phase 100 percent of the time. By contrast, when $I$ is equal to 0 there is no synchronization between the two economies.

The diffusion index in equation (3) instead measures, at any point in time, the percentage of cross-sectional units that are experiencing a recession (or expansion). Consequently, the diffusion index of recessions is equal to 1 if all of the units are in recession and, by contrast, is equal to 0 if they are all experiencing an expansion

$$
D_{t}=\frac{1}{n} \sum_{i=1}^{n} S_{i, t}
$$

We summarize the concordance between the states' business cycles and the national economy in Table 6 for three subperiods.

For the first subperiod, before the 1980s, on average, the concordance of the 48 states with the national economy is 85 percent. It becomes 77 percent for the period between 1983 and 1992 and 73 percent after 1992. These values are consistent with Owyang, Piger, and Wall (2005)'s findings, which report, between 1979 and 2002, an average concordance around 80 percent. The decrease in the level of synchronization is consistent with the findings and theoretical explanations put forward by Krugman (1991), according to whom economic and financial integration among states favors a process of concentration of industries and sectoral specialization, thus leading to asymmetric shocks and time-diverging business cycles. A decreasing level of synchronization in the U.S. has also been found by Partridge and Rickman (2005) while analyzing regional cycle asymmetries between 1971 and 1998. Their conclusion is that synchronization declines after the late 1980s. Quite interestingly, they argue that while the U.S. is commonly considered as a benchmark for the feasibility of the optimal common currency area, the observed time-diverging pattern of states' cycles does not support this idea. A similar result is also reported by Artis, Dreger, and Kholodilin (2009) who found no evidence of convergence across states' business cycles in the U.S.

Figure 2 illustrates the diffusion index of recessions. At a glance, we observe that the diffusion index shows that after the late 1980s, both expansions and recessions are weakly diffused in comparison to the 1970s and early 1980s. Weaker diffusion of economic phases implies declining synchronization and increasing timing differences across states over time, a result that is clearly in line with the findings from the concordance index analysis.

From a policy viewpoint, lower synchronization of economic phases has important implications for regional policies that try to tackle economic inequalities across states and aim to provide social and territorial cohesion within the U.S. Since the diffusion of economic growth across spatial units became recently weaker, significant spillovers from developed to low-income spaces do not take place (Petrakos and Saratsis 2000). 


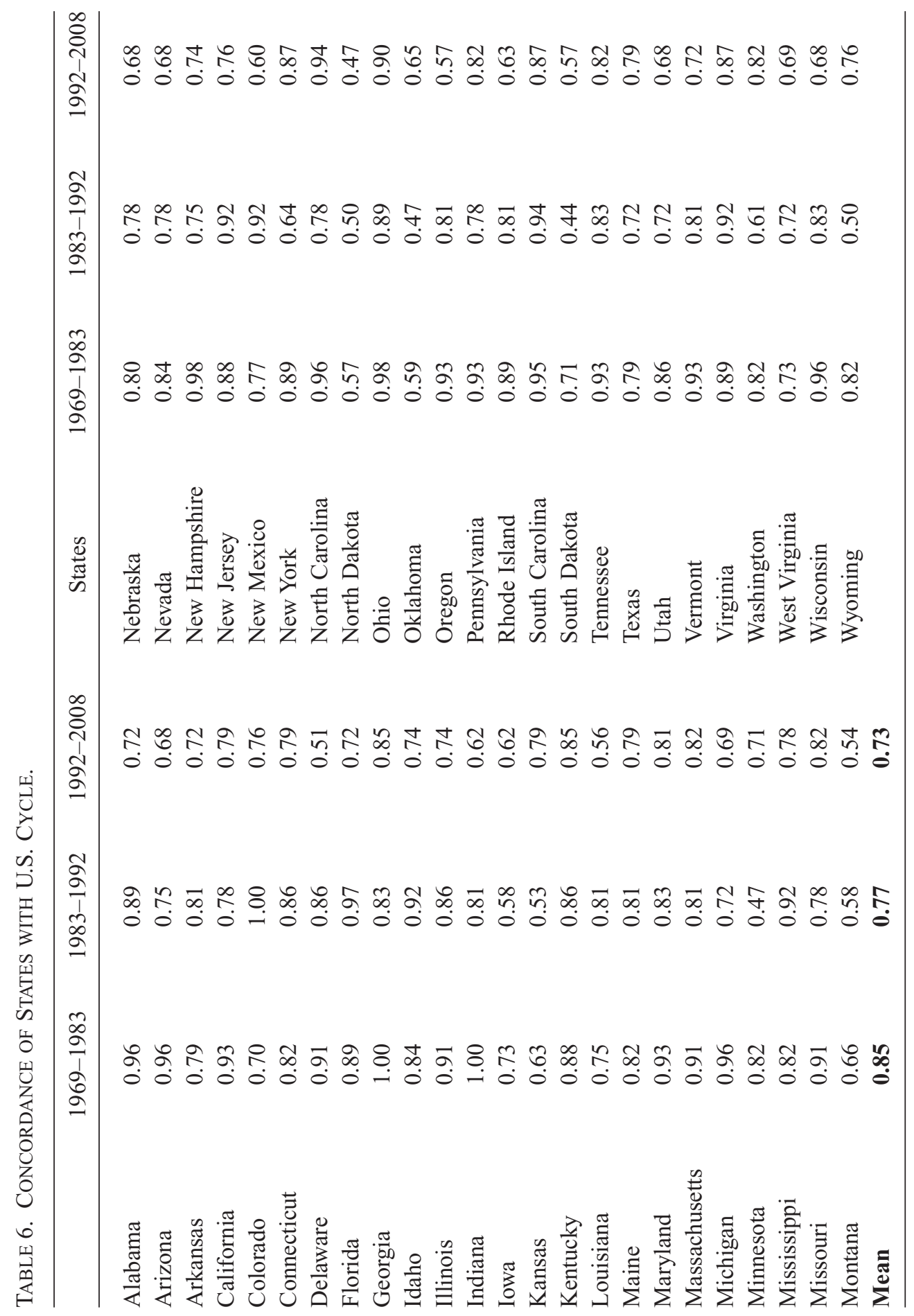




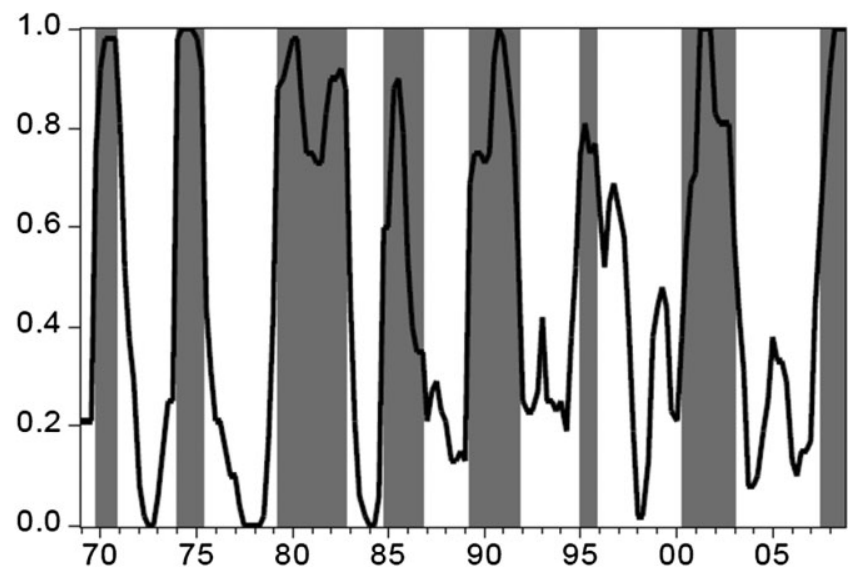

FIGURE 2. DIFFUSION OF RECESSIONS.

Note: Gray shaded areas represent the national recessions.

We, therefore, understand that dealing with the regional inequality in the U.S. is a more difficult task than initially understood.

Amplitude differences across state cycles. An important feature of the state cycles that might play a critical role in shaping the evolution of income disparities across states is represented by their different amplitudes. The evaluation of the extent to which there are differences in amplitude is therefore the object of the present subsection. Following Carlino and Sill (2001), we measure the amplitude of the business cycles by calculating the standard deviation of a cycle over time. Table 7 summarizes for each state and three subperiods, the cycle amplitudes.

Before 1980s (for first subperiod) we notice a wide variation of amplitudes across states. The mean amplitude across all states is 0.014 during this period. In order to provide a measure of dispersion in amplitudes across states, we report the coefficient of variation, in the last row of Table 7. The values of 0.46 over the 1969-1983 period indicate the existence of wide amplitude differences across states, a result in line with Carlino and Sill (2001) who found considerable differences in the amplitudes of U.S. regions. However, after the 1980 s the picture changes as the coefficient of variation now becomes 0.27 for 1983-1992 and 0.24 for the 1992-2008 period; i.e., compared with the initial period, amplitude differences across states have declined considerably over time.

Overall, a very interesting feature appears to emerge from the analysis of timing and amplitude characteristics of the state cycles: after the early 1990s, the states become less similar with respect to the timing of their cycles but more similar with respect to their amplitudes. This feature has some important implications about the short-run mechanisms of income disparities. Before the 1980s, the large variation in cycle amplitudes appears to be an important determinant of disparities in the short run, but 


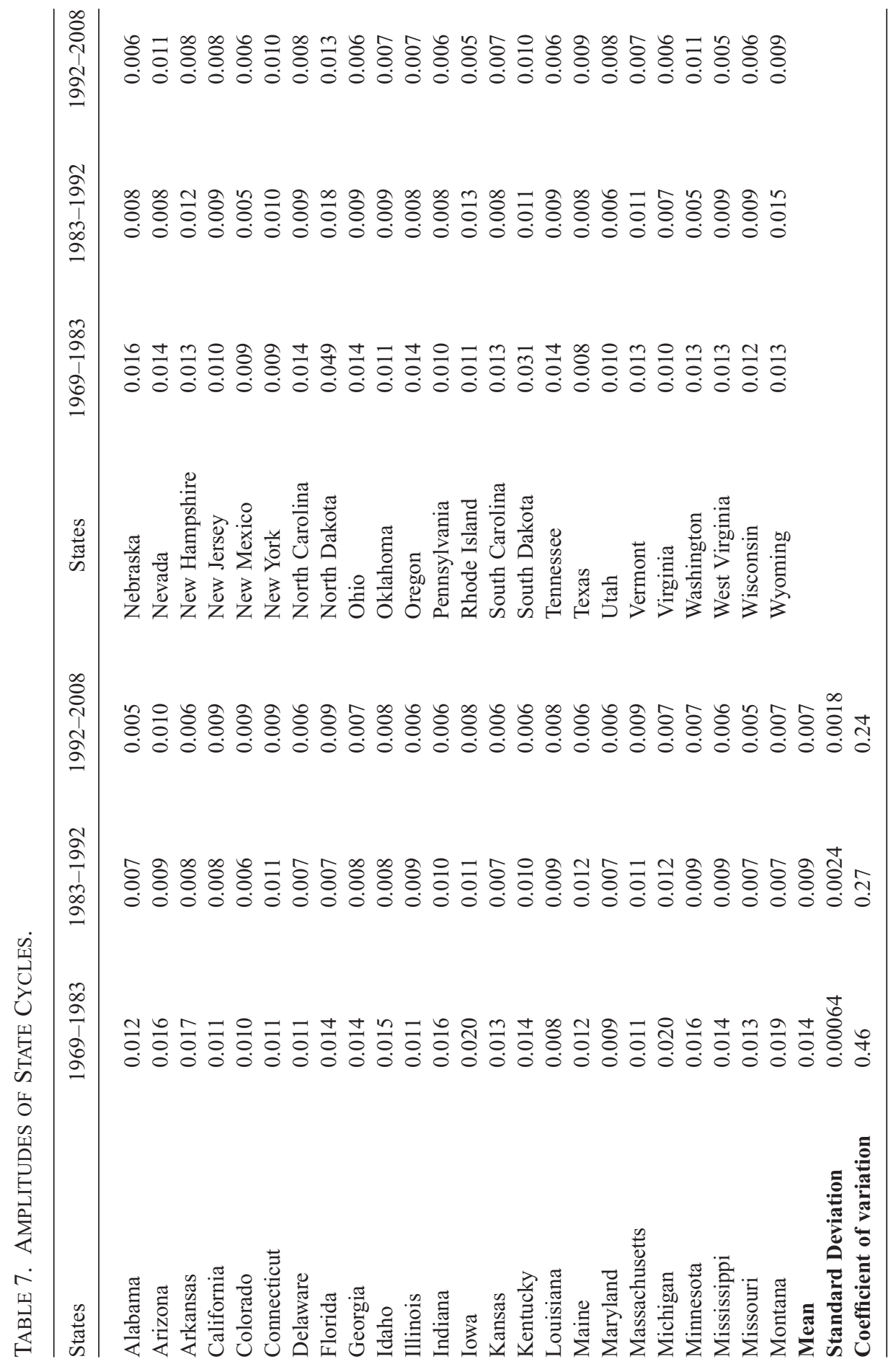


the role played by this factor tends to decline as the variation in amplitudes declines. Indeed, from the 1990s onward, it seems that the main driver behind the short-run dynamics of cross-sectional income disparities is now represented by the differences in the timing of the cycles. In the next section, we will concentrate on this specific issue and try to disentangle more formally the role played by amplitude and timing differences across states on the short-run evolution of the cross-sectional disparities.

\section{Short-Run Dynamics of Income Disparities: Does Timing or Amplitude Matter?}

In order to analyze the evolution of income disparities in the short run, the object of the analysis carried out in this section is de-trended income as de-trending obviously enables us to focus exclusively on the type of dynamics we aim to study, having got rid of those dynamics that are instead related to the long-run.

As anticipated, we consider two possible short-run factors that might drive the evolution of income disparities across states: differences in amplitudes and differences in timing of states' business cycles. In the literature, a number of studies have analyzed the tendency of amplitude and timing of cycles to converge (or diverge). In particular, differences in cycle amplitudes across U.S. regions have been documented by Carlino and Sill (2001) and Owyang, Piger, and Wall (2005) who also suggest a number of economic explanations for the observed cross-sectional variation. According to these authors, the cyclical response of a region depends primarily on its industrial structure and, in particular, on the share of employment in the manufacturing sector. In addition, regional differences in the responsiveness to changes in monetary policy or in oil price as well as differences in the demographical structure have also been indicated as possible influencing factors. As for timing differences, as already seen in the third section, much attention has been devoted in the literature to the analysis of synchronization among state cycles. However, to our knowledge, no study has ever investigated the role of amplitude and timing differences as short-run drivers of cross-sectional income disparities.

From a mechanical point of view, the two drivers might operate as follows. Let us consider de-trended income over time for two states and assume that, at the initial time, de-trended income is the same in the two states. Now, as shown in Figure 3, suppose the cycles of the two states are perfectly synchronized with each other while they differ in terms of amplitude. In such an extremely simplified instance, therefore, any (detrended) income difference between the two states must be exclusively due to differences in the size of their cyclical swings. Alternatively, as in Figure 4, suppose the cycles of the two states differ only in terms of timing while the amplitude of the swings is identical. Therefore, in this case, the evolution of disparities is exclusively due to the differences in the timing across the cycles of two economies.

In reality, not only the two figures represent extreme simplifications of the evolution of the disparities due to each of the factors, but the two factors obviously coexist, making the short-run dynamics of income disparities quite a complex phenomenon. In 


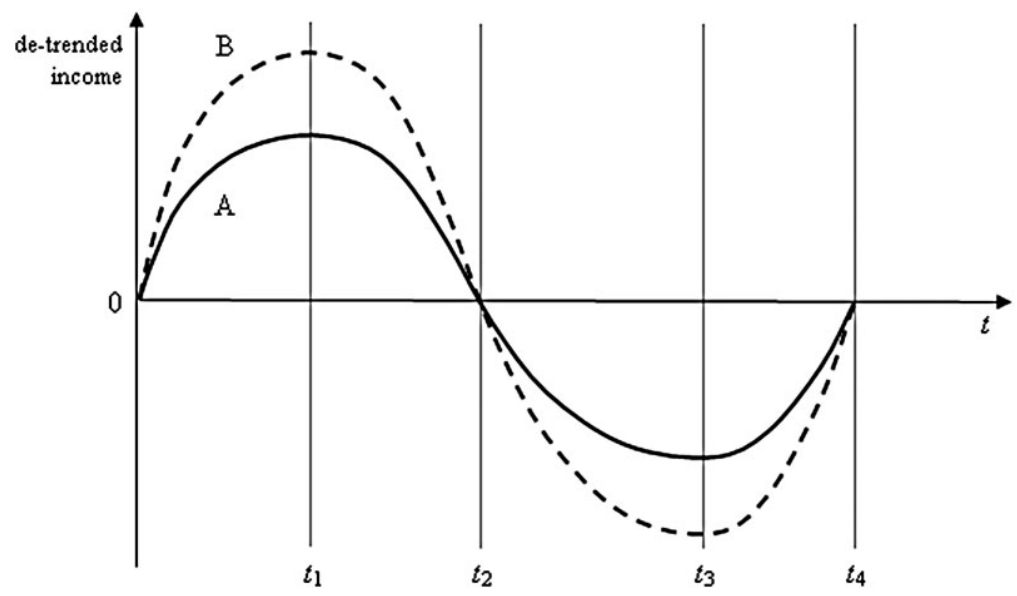

Figure 3. AMPLITUdE DifFERENCES.

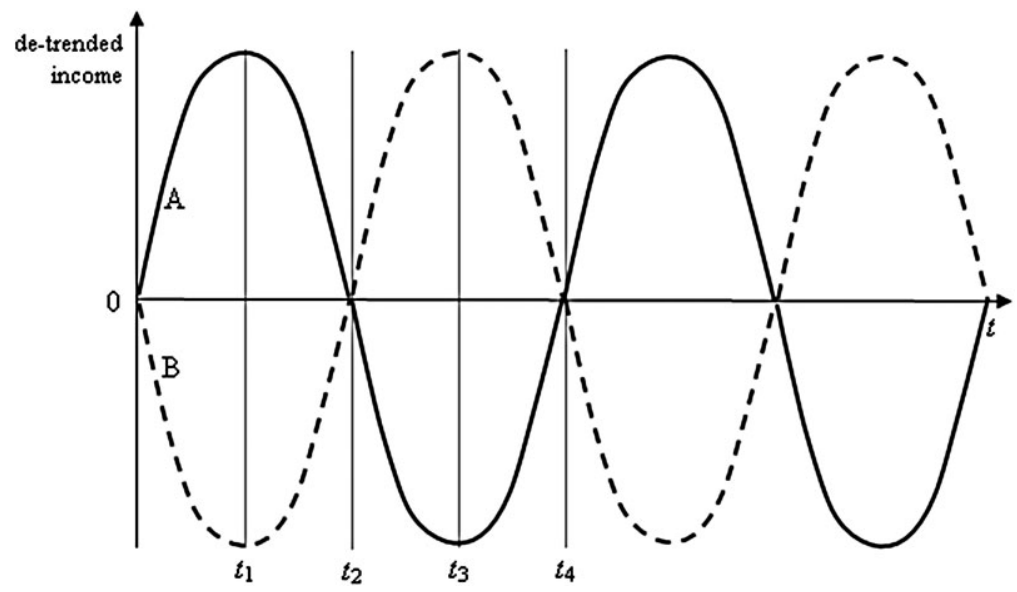

Figure 4. TIMING DifFERENCES.

order to try to disentangle these dynamics and assess the relative importance of timing and amplitude differences, we consider a vector autoregression (VAR) system and, using Cholesky variance decomposition, we evaluate the amount of shocks to disparities explained by timing differences across state cycles. Operatively, to calculate disparities we de-trend the per capita personal income series (in logs) of the 48 U.S. states and calculate the cross-sectional variance over time:

$$
D I S_{t}=\frac{\sum_{i=1}^{n}\left(C Y C_{i, t}-C \bar{Y} C_{t}\right)^{2}}{n-1}
$$




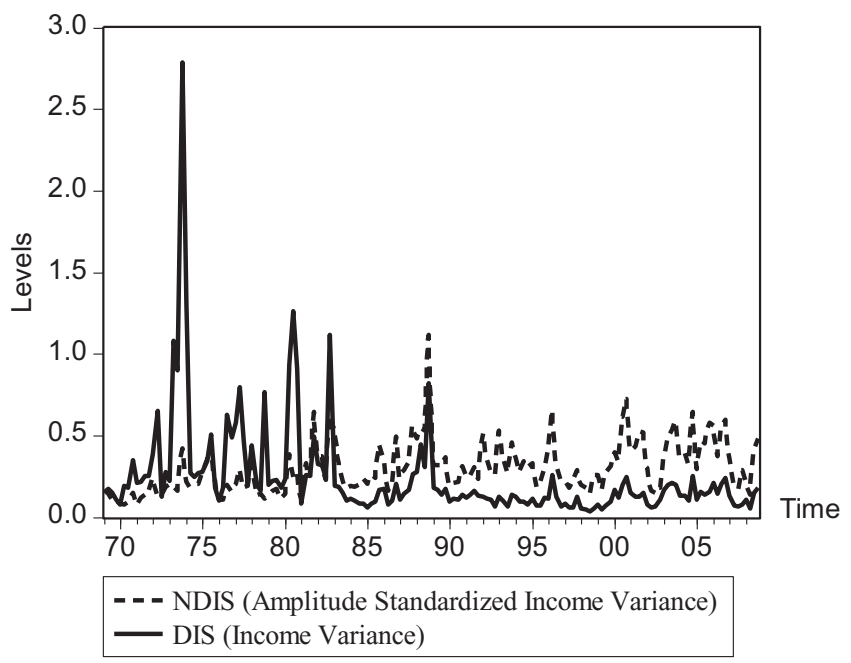

Figure 5. EVOLUTION of Disparities In De-TRENDED InCOMES.

where $C Y C_{i, t}$ is the HP de-trended per capita income of state $i$ at time $t$.In order to neutralize the differences in cycle amplitude and thus isolate the effect of timing differences, we follow Carlino and Sill (2001) as well as the OECD's procedure for amplitude standardization of the cycles: in each of the three subperiods, we divide each state's de-trended per capita income series by its standard deviation, thereby homogenizing the amplitudes of the cycles:

$$
N C Y C_{i, t}=\frac{C Y C_{i, t}}{\sigma_{i}}
$$

where $\sigma_{i}$ is the standard deviation of the de-trended per capita income series of state $i$. Having standardized the cycles with respect to their amplitudes, we then calculate the cross-sectional variance, at any point in time, using $N C Y C$. The resulting variable, $N D I S$, therefore represents the amount of disparities mostly due to timing differences across states, having removed away amplitude and trend growth differences:

$$
N D I S_{t}=\frac{\sum_{i=1}^{n}\left(N C Y C_{i, t}-N C \bar{Y} C_{t}\right)^{2}}{n-1}
$$

In Figure 5, we present the evolution of DIS and NDIS in the analyzed period. Hence, the bivariate VAR system we consider is the following:

$$
D I S_{t}=c+\vartheta_{1} D I S_{t-1}+\theta_{1} N D I S_{t-1}+\ldots+\vartheta_{p} D I S_{t-p}+\theta_{p} N D I S_{t-p}+\varsigma_{t}
$$




$$
N D I S_{t}=d+\gamma_{1} D I S_{t-1}+\phi_{1} N D I S_{t-1}+\ldots+\gamma_{p} D I S_{t-p}+\phi_{p} N D I S_{t-p}+\eta_{t}
$$

which we estimate for each of the three subperiods, using a lag length of 5 for each subperiods. Finally, we move to the last step and apply Cholesky variance decomposition, i.e., a tool that specifically allows to determine the proportion of the variance of a variable caused by shocks to a second variable. Carlino and Sill (2001), for example, use Cholesky variance decomposition to estimate, for each U.S. Bureau of Economic Analysis region, the proportion of variation in per capita income attributed to cyclical and trend shocks. Our target is to find out the proportion in cross-sectional variance (DIS), which could be attributed to the component of disparities ascribed exclusively to timing $(N D I S)$. The decomposition is implemented for a 10-period time horizon; this means that we evaluate not only the simultaneous impact of timing differences on disparities, but also the impact of up to 10-quarter lagged shocks to timing differences on the evolution of disparities.

Decomposition results are presented in Table 8 for three subperiods. ${ }^{5}$ It is evident that, before 1983, only about 32-34 percent of the disparities can be attributed to timing differences across states; in contrast, about 64-84 percent is attributed to timing differences between 1983 and 1992 and 76-83 percent of the disparities is due to timing differences across states after 1992. Therefore, we can argue that timing differences across states' business cycles become an increasingly important factor in the evolution of regional disparities in the U.S. This result is consistent with the main

Table 8. Cholesky Variance Decomposition: \% OF Shock to Disparities due to TIMING DIFFERENCES.

\begin{tabular}{|c|c|c|c|c|c|c|}
\hline \multirow[b]{2}{*}{ Period } & \multicolumn{2}{|c|}{ 1969-1983 } & \multicolumn{2}{|c|}{ 1983-1992 } & \multicolumn{2}{|c|}{ 1992-2008 } \\
\hline & $\%$ of shocks & s.e. & $\%$ of shocks & s.e. & $\%$ of shocks & s.e. \\
\hline 1 & 34.54 & $8.50 \mathrm{E}-05$ & 84.31 & 2.22E-05 & 83.54 & 8.70E-06 \\
\hline 2 & 35.55 & $9.36 \mathrm{E}-05$ & 84.02 & $2.35 \mathrm{E}-05$ & 88.45 & $1.05 \mathrm{E}-05$ \\
\hline 3 & 32.63 & $9.82 \mathrm{E}-05$ & 77.94 & $2.76 \mathrm{E}-05$ & 83.32 & $1.16 \mathrm{E}-05$ \\
\hline 4 & 33.30 & $9.87 \mathrm{E}-05$ & 77.30 & $2.79 \mathrm{E}-05$ & 77.50 & $1.20 \mathrm{E}-05$ \\
\hline 5 & 32.69 & $1.00 \mathrm{E}-04$ & 69.64 & $3.06 \mathrm{E}-05$ & 77.76 & $1.21 \mathrm{E}-05$ \\
\hline 6 & 31.76 & 0.000101 & 68.40 & 3.09E-05 & 77.07 & $1.22 \mathrm{E}-05$ \\
\hline 7 & 31.90 & 0.000102 & 68.15 & $3.09 \mathrm{E}-05$ & 76.98 & $1.22 \mathrm{E}-05$ \\
\hline 8 & 32.41 & 0.000102 & 68.15 & $3.10 \mathrm{E}-05$ & 76.89 & $1.22 \mathrm{E}-05$ \\
\hline 9 & 32.44 & 0.000102 & 66.30 & $3.15 \mathrm{E}-05$ & 76.85 & $1.23 \mathrm{E}-05$ \\
\hline 10 & 32.44 & 0.000102 & 66.41 & $3.16 \mathrm{E}-05$ & 76.58 & $1.23 \mathrm{E}-05$ \\
\hline
\end{tabular}

Note: The s.e. column reports the forecast error of the NDIS variable for each forecast horizon. 
message conveyed in the third section, i.e., amplitude differences across states tend to fade out while timing differences get more important over time. As mentioned earlier, the increasing role of timing differences is crucial also from a policy perspective. Since economic growth tends to diffuse weakly from developed states to poorer areas due to lower synchronization of economic phases, maintaining regional economic equality becomes quite a complex phenomenon and a difficult task for policy makers.

\section{Conclusions}

In this paper, we studied explicitly the short-run nature of income disparities across 48 conterminous states between 1969 and 2008.

First, by estimating the relationship between cross-sectional income disparities and a measure of the business cycle, we characterized the short-run behavior of the disparities across states. In particular, we found that disparities move counter-cyclically before the early 1980s, follow an ambiguous pattern between 1983 and 1992 and tend to move pro-cyclically afterward. We suggest that these patterns are most probably explained by the changes in the direction of factor flows across states that favor developed or poorer locations in different time periods (Fan and Casetti 1994).

Second, we demonstrated that there exist sizable differences in the timing and amplitudes of the cycles of the states. Furthermore, we noted that differences in timing were particularly evident recently, parallel to a decline in amplitude differences. Finally, through bivariate VARs and Cholesky variance decomposition, we confirmed that, as a mechanism, differences in timing of the cycles across states tend to be the major driver of the disparities while the impact of amplitude differences tends to fade away.

These findings on short-run regional disparities have important implications both for analysts and policy makers. For the analysts, when income disparities follow a distinct cyclical pattern in the short run, the choice of the period of analysis becomes of great importance. If the aim of the researchers is to recover the long-run dynamics of income disparities, the analyzed time period must include exactly one (or more) entire business cycles. Failing to do so, runs the risk of introducing a bias toward convergence or divergence depending on the pro- or counter-cyclical nature of disparities and on which phases are overrepresented.

From the perspective of the policy maker it is important to discriminate between the short-run component of the disparities and the long-run one. Clearly, the type of intervention that might be called upon by an increase in disparities due to the short-run component is likely to be quite different from those policies aimed at tackling a long-run. Most importantly, we have understood that regional policy in the U.S. is likely to be more important during booms than slumps since inequalities tend to follow a pro-cyclical pattern recently. Moreover, an important lesson that can be drawn from our results is that dealing with regional inequalities in the U.S. is harder than initially understood since economic growth creates persistently new inequalities no matter how other factors influence the disparities. 


\section{NOTES}

1. For instance, Rodriquez-Pose and Fratesi (2007) found that most Southern European countries exhibit increasingly pro-cyclical regional disparities over time.

2. In what follows, $C Y C$ denotes the national business cycle while $C Y C_{i}$ denotes the cycle of state $i$.

3. The maximum number of lags has been determined by using the rule of thumb provided by Schwert (1989).

4. We also run a Prais-Winsten regression (Prais and Winsten 1954) to address autocorrelation. The results are very similar. Therefore, we do not report them here but they are included in Appendix C.

5. In Cholesky variance decomposition one needs to assume which variable propagates the other. Here we assume that timing differences propagates the interactions among two variables.

6. The details of the algorithm are obtained from manual of BUSY 4.1 software.

\section{REFERENCES}

Artis, M., and W. Zhang. 1999. Further evidence on the international business cycle and the ERM: Is there a European business cycle? Oxford Economic Papers 51: 120-132.

Artis, M., M. Marcellino, and T. Proietti. 2003. Dating the Euro area business cycle. CEPR discussion papers 3696.

Artis, M., C. Dreger, and K. Kholodilin. 2009. Common and spatial drivers in regional business cycles. Berlin: DIW.

Azzoni, C.R. 2001. Economic growth and regional income inequality in Brazil. The Annals of Regional Science 35(1): 133-152.

Barro, R.J., and S. Sala-i-Martin. 1991. Convergence across States and Regions. Brookings Papers on Economic Activity 22(1): 107-182.

Berry, B. 1988. Migration reversals in perspective: The long wave evidence. International Regional Science Review 11: 245-251.

Breusch, T.S. 1978. Testing for autocorrelation in dynamic linear models. Australian Economic Papers 17: 334-355.

Bry, G., and C. Boschan. 1971. Cyclical analysis of time series: Selected procedures and computer programs. NBER technical paper, no 20.

Carlino, G., and K. Sill. 2001. Regional income fluctuations: Common trends and common cycles. The Review of Economics and Statistics 83: 446-456.

Chatterji, M., and J.H.L. Dewhurst. 1996. Convergence clubs and relative economic performance in Great Britain: 1977-1991. Regional Studies 30(1): 31-39.

Christiano, L., and J. Fitzgerald. 2000. The band pass filter. International Economic Review 44(2): 435-465.

Cowell, F.A. 2008. Inequality: Measurement. In The new palgrave dictionary of economics, 2nd ed., ed. S.N. Durlauf, and L.E. Blume, 282-291. Basingstoke: Palgrave Macmillan.

DeVol, R.C., P. Wong, J. Catapano, and G. Robitshek. 1999. America's high-tech economy. Growth, development, and risks for metropolitan areas. Santa Monica, CA: Milken Institute.

Dewhurst, J.H.L. 1998. Convergence and divergence in regional household incomes per head in the United Kingdom, 1984-93. Applied Economics 30: 31-35.

Dickey, D.A., and W.A. Fuller. 1979. Distribution of the estimators for autoregressive time series with a unit root. Journal of the American Statistical Association 74: 427-431.

Dimelis, S., and A. Livada. 1999. Inequality and business cycles in the U.S. and European Union countries. International Advances in Economic Research 5(3): 321-338.

Fan, C.C., and E. Casetti. 1994. The spatial and temporal dynamics of US regional income inequality, 1950-1989. Annals of Regional Science 28: 177-196. 
Fatás, A. 1997. EMU: Countries or regions? Lessons from the EMS experience. European Economic Review 41: 743-751.

Firebaugh, G. 2003. The new geography of global income inequality. London: Harvard University Press.

Godfrey, L.G. 1978. Testing against general autoregressive and moving average error models when the regressors include lagged dependent variables. Econometrica 46: 1293-1302.

Hall, V., and J. McDermott. 2004. Regional business cycles in New Zealand: Do they exist? What might drive them? Motu Working Paper 04-10.

Harding, D., and A. Pagan. 2002. A comparison of two business cycle dating methods. Journal of Economic Dynamics and Control 27: 1681-1690.

Hirschman, A. 1958. The strategy of economic development. New Haven, CT: Yale University Press.

Hodrick, R., and E.C. Prescott. 1997. Postwar U.S. business cycles: An empirical investigation. Journal of Money, Credit and Banking 29(1): 1-16.

Kim, S. 1998. Economic integration and convergence: U.S. regions, 1840-1987. The Journal of Economic History 58(4): 1016-1042.

Krugman, P.R. 1991. Geography and trade. Cambridge, MA: MIT Press.

Kuznets, S. 1953. The shares of upper income groups in income and saving. New York: NBER.

Levenberg, K. 1944. A Method for the solution of certain non-linear Problems in least squares. The Quarterly of Applied Mathematics 2: 164-168.

Magrini, S. 1999. The evolution of income disparities among the regions of the European Union. Regional Science and Urban Economics 29(2): 257-281. Elsevier.

Marquardt, D. 1963. An Algorithm for least-Squares estimation of nonlinear parameters. SIAM Journal on Applied Mathematics 11(2): 431-441.

Mendershausen, H. 1946. Changes in income distribution during the Great Depression. New York: NBER.

Mitchener, J.K., and I.W. McLean. 1999. US Regional growth and convergence, 1880-1980. The Journal of Economic History 59(4): 1016-1042.

Montoya, L.M., and J. Haan. 2007. Regional business cycle synchronization in Europe. Bruges European Economic Research Papers, BEER paper Nr. 11.

Myrdal, G. 1957. Economic theory and underdeveloped regions. London: University Paperbacks, Methuen.

Owyang, M.T., J.M. Piger, and H.J. Wall. 2005. Business cycle phases in US states. The Review of Economics and Statistics 87: 604-616.

Partridge, M.D., and D.S. Rickman. 2005. Regional cyclical asymmetries in an optimal currency area: An analysis using US state data. Oxford Economic Papers 57: 373-397.

Pekkala, S. 2000. Aggregate economic fluctuations and regional convergence: The Finnish case 1988-1995. Applied Economics 32: 211-219.

Perroux, F. 1970. A note on the concept of growth poles. In Regional economics theory and practice, ed. D. McKee, R. Dean, and W. Leahy, 93-103. New York: Free Press.

Petrakos, G., and P. Artelaris. 2009. Regional convergence revisited: A WLS Approach. Growth and Change 40(2): 319-331.

Petrakos, G., and Y. Saratsis. 2000. Regional inequalities in Greece. Papers in Regional Science 79: 57-74.

Petrakos, G., A. Rodriquez-Pose, and A. Rovolis. 2005. Growth, integration, and regional disparities in the European Union. Environment and Planning 37: 1837-1855.

Prais, S.J., and C.B. Winsten. 1954. Trend estimators and serial correlation. Cowles Commission Discussion Paper No. 383, Chicago.

Quah, D.T. 1996. Aggregate and regional disaggregate fluctuations. Center for Economic Performance Discussion Paper no. 275.

Rey, S., and B. Montouri. 1999. US Regional income convergence: A spatial econometric perspective. Regional Studies 33(2): 143-156. 
Rodriquez-Pose, R., and U. Fratesi. 2007. Regional business cycles and the emergence of sheltered economies in the southern periphery of Europe. Growth and Change 38: 621-648.

Schwert, G.W. 1989. Tests for unit Root: A Monte Carlo investigation. Journal of Business and Economic Statistics, American Statistical Association 7(2): 147-159.

Terassi, M. 1999. Convergence and divergence across Italian regions. Annals of Regional Science 33: 491-510.

Theil, H. 1967. Economics and information theory. Amsterdam: NorthHolland.

Tortosa-Ausina, E., F. Perez, and M. Mas. 2005. Growth and convergence profiles in the Spanish provinces 1965-1997. Journal of Regional Science 45(1): 147-182.

Zarnowitz, V., and A. Ozyildirim. 2006. Time series decomposition and measurement of business cycles, trends and growth cycles. Journal of Monetary Economics 53(7): 1717-1739.

\section{Appendix A Bry and Boschan (1971) Quarterly Algorithm}

I On the HP de-trended series. a Spencer moving average is applied in order to obtain the Spencer's curve.

II HP de-trended series are corrected for outliers. Outliers are the observations that are at least 3.5 standard deviations away from the mean. We replace outliers by their equivalent value on the Spencer's curve. Applying a Spencer moving average on the outlier corrected series creates an outlier-corrected Spencer's curve.

III A $2 \times 4$ centered moving average (MA) is applied on the outlier-corrected data to obtain the "first cycle" curve. $2 \times 4$ centered MA means that a four-term centered MA is applied on a two-term centered moving average cycle.

IV A first set of turning points is searched within the first cycle curve and then these turning points have been used to look for the corresponding turning points on the Spencer's curve. The local minima/maxima have been searched in every five quarters. Therefore, the window length is five quarters.

$\mathrm{V}$ A minimum cycle length restriction is imposed so that any cycle from peak (trough) to peak (trough) has at least a duration of five quarters. It is checked whether the peaks and troughs orderly alternate, i.e., peak-trough-peak, and the alternation is imposed if necessary.

VI The Months for Cyclical Dominance (MCD). "the minimum month-delay for which the average of absolute deviations of growth in Spencer's cycle is larger than that in the irregular component" is computed. After that a MA of length MCD is applied on the previously outlier-corrected series. A new set of turning points is searched on the basis of the complementary turning points that were found on the Spencer's curve. Again, a minimum cycle length restriction is imposed (five quarters) and orderly alternation of the turning points is imposed.

VII This last set of turning points is cleaned by discarding the points corresponding to the first and last two observations. A minimum phase length restriction of 2 quarters is imposed. Thus, the final set of turning points is obtained. ${ }^{6}$ 


\section{Appendix B Variables and Data Sources}

\begin{tabular}{|c|c|}
\hline Variables & Definition \\
\hline $\mathrm{CV}$ & $\begin{array}{l}\text { Coefficient of variation as a measure of cross-sectional dispersion of } \\
\text { income across states calculated using per capita real personal income } \\
\text { net of transfers. }\end{array}$ \\
\hline CVHP & Hodrick-Prescott de-trended coefficient of variation. \\
\hline CYC & $\begin{array}{l}\text { Hodrick-Prescott de-trended per capita real personal income net of } \\
\text { transfers series. It denotes national cycle unless sub-script } i \text { exists. }\end{array}$ \\
\hline DIS & $\begin{array}{l}\text { Cross-sectional variance of income calculated using de-trended personal } \\
\text { income series of states. }\end{array}$ \\
\hline Ineq & General abbreviation used to denote income inequalities across states \\
\hline NCYC & $\begin{array}{l}\text { Hodrick-Prescott de-trended and amplitude adjusted per capita real } \\
\text { personal income net of transfers series. }\end{array}$ \\
\hline NDIS & $\begin{array}{l}\text { Cross-sectional variance of income calculated using de-trended and } \\
\text { amplitude standardized personal income series of states. }\end{array}$ \\
\hline $\mathrm{p}$ & Population \\
\hline RPI & $\begin{array}{l}\text { Per capita real personal income net of current transfers receipts. } \\
\text { All income series are deflated using the 1982-1984 U.S. city average } \\
\text { national consumer price index. }\end{array}$ \\
\hline rpi & Gross real personal income net of current transfer receipts. \\
\hline Theil & Theil index calculated to measure income inequalities across states \\
\hline TheilHP & Hodrick-Prescott de-trended Theil index \\
\hline WCV & Population-weighted coefficient of variation \\
\hline WCVHP & Hodrick-Prescott de-trended population-weighted coefficient of variation \\
\hline $\mathrm{x}$ & Relative population of a state with respect to aggregate population \\
\hline
\end{tabular}

Data Sources: Personal income, population and current transfer receipts series are obtained from U.S. Bureau of Economic Analysis (BEA). U.S. city average consumer price index is obtained from U.S. Bureau of Labor Statistics (BLS).

Software: The analysis in this paper has been implemented using EVIEWS 4.0, R 2.12 and BUSY 4.1. 
332 GROWTH AND CHANGE, JUNE 2014

\section{Appendix C Prais-Winsten Regression}

Dependent variable:

Population-weighted coefficient of variation

\begin{tabular}{lcccl} 
Coefficients & $1969-2008$ & $1969-1983$ & $1983-1992$ & $1992-2008$ \\
\hline$\alpha$ & -0.00004 & -0.0003 & $-3.43 \mathrm{e}-06$ & -0.0002 \\
$\beta$ & $-1.88 \mathrm{e}-07$ & $-\mathbf{1 . 1 8 e - 0 5 * * *}$ & 0.0009 & $\mathbf{9 . 7 2 e - 0 6 * * *}$ \\
Autoregressive error & 0.73 & 0.68 & 0.78 & 0.65 \\
\hline
\end{tabular}

Dependent variable:

Theil index

\begin{tabular}{|c|c|c|c|c|}
\hline Coefficients & 1969-2008 & 1969-1983 & 1983-1992 & 1992-2008 \\
\hline$\alpha$ & $-9.85 e-06$ & $-4.86 e-06$ & $3.46 \mathrm{e}-06$ & $3.08 \mathrm{e}-05$ \\
\hline$\beta$ & $6.80 \mathrm{e}-08$ & $-4.02 \mathrm{e}-07^{* * *}$ & $1.42 \mathrm{e}-07$ & $5.27 \mathrm{e}-07 * * *$ \\
\hline Autoregressive error & 0.74 & 0.43 & 0.81 & 0.71 \\
\hline Dependent variable: & \multicolumn{4}{|c|}{ Unweighted coefficient of variation } \\
\hline Coefficients & 1969-2008 & 1969-1983 & 1983-1992 & 1992-2008 \\
\hline$\alpha$ & $1.36 \mathrm{e}-05$ & 0.0002 & -0.0002 & $8.89 \mathrm{e}-05$ \\
\hline$\beta$ & $9.10 \mathrm{e}-07$ & $-4.11 \mathrm{e}-06$ & $-8.99 \mathrm{e}-06$ & $6.97 \mathrm{e}-06^{* * *}$ \\
\hline Autoregressive error & 0.74 & 0.60 & 0.91 & 0.66 \\
\hline
\end{tabular}

Significance levels: * $10 \%, * * 5 \%, * * * 1 \%$. 